\title{
3.2 Das Phänomen des nationalsozialistischen und sowjetkommunistischen Totalitarismus und der Terrorvergleich
}

Vom politischen Selbstverständnis Laskys war die internationale Zeitschrift Der Monat grundsätzlich antitotalitär ausgerichtet und konzipiert. ${ }^{621}$ Die totalitären Herrschaftssysteme, d.h. die Einparteienregime des Nationalsozialismus und Sowjetkommunismus (Stalinismus/Nachstalinismus), wurden einerseits in der Regel im Hinblick auf die Geschichte der christlich-abendländischen Kultur als neuartige Herrschaftsmodelle apostrophiert, ${ }^{622}$ andererseits als ein grundsätzliches Gegenmodell zur liberalen Demokratie angesehen, sodass zahlreiche Autoren aus unterschiedlichsten Anlässen mit Blick auf »die« Demokratietheorie und die politische Alltagswelt und -praxis sowie rechtsstaatliche Wirklichkeit zu diesem Themenkomplex veröffentlichten. ${ }^{623}$

nen deutschen Ausgabe der Studie von Norman Cohn und liegt somit außerhalb des für diesen Teil der vorliegenden Arbeit zugrunde liegenden Untersuchungszeitraumes.

621 Siehe exemplarisch Laskys Beitrag in: Der Monat 1 (1949), H. 4, S. 125 f., sowie ders., Die Moskauer Geständnisse. Gedanken über Ketzerei und Opposition im totalen Staat, in: Der Monat 3 (1951), H. 36, S. 648-654 (Rezension).

622 Siehe hierzu exemplarisch C. f. Hudson, Professor Toynbee und der Westen. Zu einem neuen Buch von Arnold ]. Toynbee, in: Der Monat 5 (1953), H. 57, S. 317-321 (Rezension).

623 Siehe hierzu aus sämtlichen Veröffentlichungen im Monat vor allem folgende Beiträge, die hier ohne Anspruch auf Vollständigkeit - in chronologischer Reihenfolge aufgeführt werden: Sidney Hook, Drei Grundzüge westlichen Denkens, in: Der Monat 1 (1948), H. 2, S. 8-17; Norbert Mühlen, Brief aus Amerika: Eine Demokratie verteidigt sich, in: Der Monat 1 (1948), H. 2, 71-77; Joseph Schumpeter, Der demokratische Kurs, in: Der Monat 1 (1949), H. 5, S. 22-28; Willy Brandt, Weitergeführte Demokratie, in: Der Monat 1 (1949), H. 5, S. 29-33; Arthur M. Schlesinger jr., Ein Sozialist und die Demokratie, in: Der Monat 1 (1949), H. 5, S. 95-98 (Rezension); Sidney Hook, John Dewey. Ein Porträt des Altmeisters des amerikanischen Ceisteslebens, in: Der Monat 1 (1949), H. 6, S. 40-46; Herbert Lüthy, Die Vierte Republik. Von Charles de Gaulle zu Henri Queuille (Teil 1), in: Der Monat 1 (1949), H. 8/9, S. 120-133, sowie ders., Die Vierte Republik. Frankreich seit seiner Befreiung (Teil 2), in: Der Monat 1 (1949), H. 10, S. 39-48; C. V. Wedgwood, Wie wächst die Macht. Über ein Buch von Bertrand de Jouvenel, in: Der Monat 1 (1949), H. 10, S. 96-98 (Rezension); Arthur M. Schlesinger jr., Politik im Zeitalter der Angst, in: Der Monat 2 (1950), H. 16, S. 339-352 (Teil I) sowie (Teil II) H. 19, S. 68-75 (hierbei handelte es sich um Auszüge seines Buches The Vital Center. The Politics of Freedom [Boston 1949]); Ludwig Bergsträsser, Alexis de Tocqueville. Kritiker und Verteidiger der Demokratie, in: Der Monat 2 (1950), H. 18, S. 608-620; Norbert Mühlen, Brief aus New York: Die Affäre Hiss, in: Der Monat 2 (1950), H. 18, S. 621-627; M[elvin] ]. L[asky], Demokratischer Humanismus, in: Der Monat 2 (1950), H. 18, S. 666-668 (Rezension); Joachim G. Leithäuser, Erziehung zur Zukunft, in: Der Monat 2 (1950), H. 20, S. 218-220 (Rezension); Isaiah Berlin, Der Einbruch des Irrationalen. Politische Ideen im 19. und 20. Jahrhundert, in: Der Monat 3 (1951), H. 28, S. 339-348 (Teil 1) sowie Der Weg zum Konformismus. Politische Ideen im. 19. und 20. Jahrhundert, in: Der Monat 3 (1951), H. 29, S. 461-469 (Teil 2); Norbert Mühlen, Brief aus New York: Amerikanische Gewerkschaften, in: Der Monat 3 (1951), H. 32, S. 153-158; Herbert Lüthy, Brief aus Paris: Stabilität oder Stagnation, in: Der Monat 3 (1951), H. 35, S. 465-476; Hans Joachim Lieber, Macht und Furcht, in: Der Monat 3 (1951), H. 35, S. 546-548 (Rezension); Karl Dietrich Bracher, Gegen die Politik der Furcht, in: Der Monat 3 (1951), H. 36, S. 661-665 (Rezension); Wilhelm Grewe, Parteienstaat - Oder was sonst?, in: Der Monat 3 (1951), H. 36, S. 563-577; Sidney Hook, Kann man die Freiheit essen?, in: Der Monat 4 (1952), H. 40, S. 339-344; Ossip K. Flechtheim, Der Idealist und der Realist, in: Der Monat 4 (1952), H. 47, S. 532 f. (Rezension); Peter de Mendelssohn, Brief aus London: Die Herrschaft der Wenigen. Zum Problem der englischen Gewerkschaften, in: Der Monat 4 (1952), H. 48, S. 581-588; Heinz-Joachim Arndt, Das Recklinghauser Gespräch, in: Der Monat 4 (1952), H. 48, S. 658-663; F[ritz] R[ené] Allemann, Das deutsche Parteiensystem. Eine politi- 
Ohne Zweifel zählte die facettenreiche Auseinandersetzung mit dem nationalsozialistischen und dem sowjetkommunistischen Totalitarismus oder auch mit dem italienischen Faschismus ${ }^{624}$ zu einem Schwerpunktthema des Monat. Nicht zuletzt vor dem Hintergrund der totalitären Erfahrungen, die ein größerer Teil der Autoren der Zeitschrift mit dem »Hitlerschen Totalitarismus« (de Mendelssohn) und/oder dem Stalinismus gemacht hatten, kann festgestellt werden, dass nach der bedingungslosen Kapitulation des >Dritten Reiches $<$ im Jahre 1945 insbesondere in den ersten Jahren des Erscheinens der internationalen Zeitschrift die Auseinandersetzung mit dem aktuellen totalitären Herrschaftsmodell sowjetischer Couleur fokussiert wurde. ${ }^{625}$ Gleichwohl besaß auch bereits in diesen ersten Jahren die vergleichende Analyse des Nationalsozialismus mit dem Stalinismus eine zentrale Bedeutung. Wie noch zu zeigen sein wird, bildete der Tod Stalins eine herausragende Zäsur, weil fortan - aufgrund der genuinen Beschreibung und Analyse des Wandlungsprozesses des kommunistischen

sche Analyse, in: Der Monat 5 (1953), H. 52, S. 365-388; Peter de Mendelssohn, Brief aus London: Unbehagen in Westmister, in: Der Monat 5 (1953), H. 56, S. 125-134; Briefe aus vier Hauptstädten: Krise des Parlamentarismus? Eine Rundfrage nach dem Befinden europäischer Volksvertretungen, in: Der Monat 5 (1953), H. 57, S. 287-297: mit Beiträgen von Gustave Stern (Paris), Fritz Brühl (Bonn), G. E. R. Gedye (Wien) sowie Gustav Mersu (Rom); Norbert Mühlen, Brief aus der Bundesrepublik: Das Land der Großen Mitte. Notizen aus dem Neon-Biedermeier, in: Der Monat 6 (1953), H. 63, S. 237-244; Colo Mann, Die einsame Menge. Bemerkungen zu David Riesmans Buch, in: Der Monat 6 (1954), H. 67 , S. 71-75 (Rezension); Alfred Cobban, Der Verfall der politischen Theorie, in: Der Monat 6 (1954), H. 69 , S. 227-237, sowie hierzu: Verfall der politischen Theorie? Politische Wissenschaftler diskutieren Alfred Cobbans These, in: Der Monat 6 (1954), H. 72, S. 598-603 (mit Beiträgen von Alfred Weber und Otto Heinrich v. d. Gablentz) und Adolf Grabowsky, Aufstieg der politischen Theorie, in: Der Monat 7 (1954), H. 73, S. 88-92; A. J. P. Taylor, Die Masse als Schreckgespenst. Zur Neuauflage von Tocquevelles >Démocratie en Amérique<, in: Der Monat 7 (1954), H. 73, S. 66-68 (Sammelrezension); Rudolf Augstein, Stimmzettel gegen Recht und Freiheit. Zu W. Martins >Das Ende aller Sicherheit<, in: Der Monat 7 (1955), H. 76, S. 362-365 (Rezension); F[ritz] René Allemann, Brief aus Westdeutschland: Bonn ist nicht Weimar, in: Der Monat 7 (1955), H. 76, S. 333-341; ders., Brief aus Bonn: Das Weltbild des Souveräns, in: Der Monat 7 (1955), H. 77, S. 402-408; ders., Brief aus Bonn: Die Nemesis der Ohnmacht (Teil 1), in: Der Monat 7 (1955), H. 80, S. 99-105, sowie Brief aus Bonn: Was ist eine demokratische Armee? Wiederbewaffnung als innenpolitische Aufgabe (Teil 2), in: Der Monat 7 (1955), H. 81 , S. 196-201; Hellmut Jaesrich, Brief aus Niedersachsen: Die Göttinger Dreitausend, in: Der Monat 7 (1955), H. 82, S. 291-301; F[ritz] René Allemann, Brief aus Bonn: Was kommt nach Adenauer, in: Der Monat 8 (1955), H. 86, S. 3-12; Alfred Kellner, Was verstehen Frauen von der Politik?, in: Der Monat 8 (1956), H. 94, S. 72-75; Walter Lippmann und Richard Rovere schreiben aus Washinghton: Walter Lippmann, Die amerikanische Verantwortung, in: Der Monat 10 (1957), H. 109, S. 76-78, sowie Richard Rovere, Die Neun von Little Rock, in: Ebd., S. 78f.; F[ritz] René Allemann, Verfassungswirklichkeit-morgen. Wenn Adenauer Bundespräsident wird, dann ..., in: Der Monat 11 (1959), H. 129, S. 9-17; ders., Brief aus Bonn: Rückblick auf eine Krise, in: Der Monat 11 (1959), H. 130, S. 6-13; Raymond Aron, De Gaulles Alleingang, in: Der Monat 12 (1960), H. 139, S. 14-22.

624 Der italienische Faschismus wurde anfangs in vielen Beiträgen unter die Kategorie totalitäres Herrschaftssystem subsumiert, sodass für den in der vorliegenden Arbeit zu untersuchenden Zeitraum eine historisch-politische und analytisch-kategoriale Unterscheidung der drei genannten politischen Herrschaftsordnungen seitens der Autoren nicht durchgehend eingehalten wurde.

625 Die qualitative Auswertung des Monat ergab eindeutig, dass auch in den ersten Jahren die Auseinandersetzung mit dem Sowjetkommunismus gegenüber dem Nationalsozialismus einen erheblich größeren Raum einnahm. 
Herrschaftssystems in der Nach-Stalin-Ära ${ }^{626}$ - die vergleichende Untersuchung und Thematisierung des Phänomens des deutschen und des sowjetischen Totalitarismus sowie der Terrorvergleich hinsichtlich des qualitativen und quantitativen Charakters im Vergleich zu den ersten fünf Jahrgängen eine geringere Bedeutung besaß.

Gewöhnlich wurde in den entsprechenden Veröffentlichungen des Monat auf die zeitgenössische Erfahrung mit dem »Jahrhundert des Totalitarismus« (Richard H. S. Crossmann) ${ }^{627}$ in erster Linie auf einer abstrakten Ebene eingegangen. In zahlreichen Beiträgen erfolgte die Auseinandersetzung (explizit oder implizit) mit dem facettenreichen Phänomen der totalitären Herrschaftsregime, ohne die zentrale Rolle der Geheimpolizei, des Terrors oder der Konzentrationslager konkret in den Brennpunkt zu rücken. Hier wurde ebendieser Themenkomplex primär im Kontext genereller und kritischer Reflexionen sowohl zur Bedeutung der Französischen Revolution von 1789 für die weitere Entwicklung der Moderne ${ }^{628}$ als auch zur Philosophie, Kultur, Literatur und Kunst beleuchtet oder im Rahmen gesellschafts- und technikkritischer Ausführungen. ${ }^{629}$

Zudem wurden in zahlreichen Fällen die nicht zuletzt wegen der politisch-ideologischen Herrschaftsinstrumente und -methoden qualitativ neuartigen Regime im Kontext der sogenannten Revolutionen des 20. Jahrhunderts, ${ }^{630}$ der Geschichte des

626 Siehe hierzu die entsprechenden Ausführungen in den Abschnitten IV.2.5 bis IV.2.8.

627 Zit. n. R[ichard] H. S. Crossmann, Buddha oder Prometheus, in: Der Monat 4 (1952), H. 46, S. 388.

628 Siehe hierzu bes. Hans Kohn, Ein Vorspiel zum totalitären Terror, in: Der Monat 3 (1951), H. 35, S. 512518, sowie Herbert Lüthy, Rivarols Jünger - oder Jüngers Rivarol?, in: Der Monat 9 (1957), H. 101, S. 56-70, der die zeitgenössischen Konsequenzen der Französischen Revolution implizit auch im Hinblick auf die Kategorie »politische Religion « untersuchte. Siehe ebenfalls mit dem Blick auf die grundsätzliche Bedeutung der Französischen Revolution als »politische Religion« für die (politischen) Revolutionen der Moderne insgesamt Alfred v. Martin, Revolution als Schicksal, in: Der Monat 2 (1950), H. 24, S. 594-597 (Rezension). Siehe auch zur Bedeutung der Französischen Revolution in Bezug auf die gesamteuropäischen historisch-politischen Folgen für das 19. Jahrhundert und mit implizitem Blick auf den Faschismus, Nationalsozialismus und Sowjetkommunismus: Karl Dietrich Bracher, Gegen die Politik der Furcht, in: Der Monat 3 (1951), H. 36, S. 661-665 (Sammelrezension). Vgl. unter diesem Aspekt auch Hans-Joachim Lieber, Macht und Furcht, in: Der Monat 3 (1951), H. 35 , S. 546-548 (Rezension) sowie Joachim G. Leithäuser, Unbarmherzige Ratio, in: Der Monat 3 (1951), H. 30, S. 655-657 (Rezension).

629 Siehe exemplarisch an dieser Stelle - ohne Anspruch auf Vollständigkeit - folgende in chronologischer Reihenfolge aufgeführten Beiträge: Franz Borkenau, Nach der Atombombe, in: Der Monat 1 (1948), H. 1, S. 9-16; Joachim G. Leithäuser, Im Gruselkabinett der Technik. Kritische Bemerkungen zur Mode des romantischen Pessimismus, in: Der Monat 3 (1951), H. 29, S. 474-486; ders., Unbarmherzige Ratio, in: Der Monat 3 (1951), H. 30, S. 655-657 (Rezension); François Bondy, Galerie der Schurken, in: Der Monat 3 (1951), H. 31, S. 88 f. (Rezension); Denis de Rougemont, Die Krankheit der Europäischen Kultur, in: Der Monat 3 (1951), H. 32, S. 115-132; Michael Freund, Die Erbsünde unserer Welt, in: Der Monat 3 (1951), H. 36, S. 656-658 (Rezension); Rudolf Hagelstange, Moderne Humanitas, in: Der Monat 4 (1951), H. 38, S. 115-123; Hilde Spiel, Der Teufel und der liebe Huxley, in: Der Monat 5 (1952), H. 51, S. 328-330 (Rezension); Wolf Jobst Siedler, Die Freiheit der Entscheidung. Zum Werk Friedrich Torbergs, in: Der Monat 5 (1953), H. 55, S. 77-81; Theodor W. Adorno, Die gegängelte Musik, in: Der Monat 5 (1953), H. 56, S. 177-183; Arnold ]. Toynbee, Mensch und Geschichte, Mensch und Geschichte, in: Der Monat 7 (1954), H. 73, S. 15-19; Ignazio Silone, Auf welcher Seite stehen wir?, in: Der Monat 7 (1954), H. 74, S. 99-105.

630 Siehe hierzu ausdrücklich Hugh Seton-Watson, Revolutionen im Zwanzigsten Jahrhundert, in: Der Monat 4 (1952), H. 42, S. 607-619. Vgl. auch die Beschreibung und Analyse der Ereignisse des 16./17. 
chinesischen Kommunismus unter $\mathrm{Mao}^{631}$ sowie der Genesis des Phänomens des (pan-)islamistischen Semitotalitarismus ${ }^{632}$ beschrieben und analysiert, ohne dass hierbei ein genuin vergleichender Blick auf den Nationalsozialismus und den Sowjetkommunismus gerichtet wurde.

Bei der komplexen Auseinandersetzung mit dem Totalitarismusphänomen kam im Monat zum Ausdruck, dass zwischen den totalitären Diktaturen in Deutschland und der Sowjetunion sowie den zeitgenössischen faschistischen, semifaschistischen bzw. autoritären Herrschaftsregimen in Europa (Italien, Spanien, Portugal) ${ }^{633}$ und Süd- und Mittelamerika (Argentinien, Panama, Nicaragua, Costa Rica) ${ }^{634}$ qualitative Differenzen bestanden. In diesem Zusammenhang wurden in den meisten, jeweils einem ganz unterschiedlichen Genre zählenden Beiträgen (eigenständiger Aufsatz,

Juni 1953 in Ostberlin sowie der sowjetischen Besatzungszone mit ausdrücklichem Bezug auf »die« revolutionäre Theorie: Ernest ]. Salter, Über den Juni-Aufstand, in: Der Monat 5 (1953), H. 59, S. 545548.Vgl. auch Ceorge Orwell, Der Hofstaat der Tiere. »Animal Farm«, in: Der Monat 1 (1949), H. 5, S. 38-54 (Teil I), H. 6 (1949), S. 10-24 (Teil II) und H. 7, S. 34-43 (Teil III), sowie die jeweils einleitenden Ausführungen der Zeitschriftenredaktion zu den einzelnen Teilen; hierbei handelte es sich um den Vorabdruck der »satirischen politischen Fabel«, die unter dem ursprünglichen englischen Titel Animal Farm zuerst in London 1945 erschien. Vgl. auch indes mit dem Fokus auf die Bedeutung der modernen Revolutionen seit 1789 als »politische Religion«: Alfred v. Martin, Revolution als Schicksal, in: Der Monat 2 (1950), H. 24, S. 594-597 (Rezension).

631 Siehe hierzu folgende Beiträge: M[elvin] ]. L[asky], Tragödie im Orient. China und die Welt, in: Der Monat 1 (1949), H. 5, S. 62-65; Christopher Rand, Brief aus Schanghai: Eine Weltstadt löst sich auf, in: Ebd., S. 66-72, sowie in diesem Zusammenhang auch Harold R. Isaacs, Kreml und Kuomintang, in: Ebd., S. 73-82; Karl A. Wittfogel, Mao und die Generallinie. Über den Einfluß des Leninismus-Stalinismus in China, in: Der Monat 4 (1952), H. 41, S. 498-507; Robert Guillain, Brief aus Hongkong: >Der Mensch lebt nicht vom Reis allein .... Die chinesische Läuterungskampagne, in: Der Monat 10 (1957), H. 109, S. 16-22; Lily Abegg, Brief aus Hongkong: Hundert Blumen und giftiges Unkraut, in: Der Monat 10 (1958), H. 113, S. 48-59, sowie A. Kashin, Die Opposition in China, in: Der Monat 10 (1958), H. 118, S. 88-90 (hierbei handelte es sich um einen Leserbrief zu dem Beitrag von Lily Abegg in H. 113).

632 Vgl. hierzu folgende Beiträge: Herbert Lüthy, Nordafrikanische Impressionen, in: Der Monat 4 (1952), H. 45, S. 292-304; ders. Brief aus Tunis: Nordafrika wird mündig. Nachträge zu einem Reisebericht, in: Der Monat 4 (1952), H. 47, S. 498-515; F[ritz] R[ené] Allemann, Panislamismus. Mythos und Realität, in: Der Monat 4 (1952), H. 48, S. 589-598; ders., Brief aus Teheran: Aus einem persischen Notizbuch, in: Der Monat 6 (1953), H. 61, S. 16-29; ders., Brief aus Ankara: Unter der Schirmmütze, in: Der Monat 6 (1954), H. 64, S. 344-356 (Teil I), sowie Brief aus Ankara: Die Dialektik des Fortschritts, in: Der Monat 6 (1954), H. 65, S. 486-496 (Teil II); Walter Laqueur, Nassers Flucht in die Außenpolitik, in: Der Monat 9 (1956), H. 97, S. 68-71; F[ritz] R[ené] Allemann, Orient im Halbdunkel, in: Der Monat 10 (1958), H. 120, S. 3-9; Edouard Sablier, Gamal Abdel Nasser. Ein Sohn der ägyptischen Erde, in: Der Monat 10 (1958), H. 120, S. 10-16.

633 Siehe zur »Salazar-Diktatur« in Portugal: V. S. Pritchett, Reise nach Portugal, in: Der Monat 8 (1956), H. 95, S. 15-25, sowie Edouard Roditi, Brief aus Lissabon: Nichts Neues in Portugal, in: Der Monat 10 (1957), H. 109, S. 44-48.

634 Siehe zum argentinischen »Peronismus«: Christopher Isherwood, Brief aus Buenos Aires: Lächelnde Diktatur, in: Der Monat 2 (1950), H. 21, S. 258-263, sowie Peter Schmid, Brief aus Buenos Aires: Perón ohne Evita, in: Der Monat 5 (1953), H. 55, S. 45-49; siehe zum »Somaza-Regime« in Nicaragua: Peter Schmid, Brief aus Managua: Der Diktator in der Zuckerfabrik, in: Der Monat 4 (1952), H. 44, S. 165-171; siehe zum »Figueres-Regime« in Costa Rica: Ders., Brief aus Costa Rica: Don Quijote und die Bürger, in: Der Monat 4 (1952), H. 45, S. 279-283; siehe zum »Remon-Regime« in Panama: Ders., Brief aus Mittelamerika: Wetterwolken am Panamakanal, in: Der Monat 4 (1952), H. 46, S. 389-394. 
Buchrezension, Romanauszug, Reiseberichte etc.) zu den internationalen Rechtsdiktaturen die qualitativen Differenzen in erster Linie in vergleichender Perspektive zum totalitären nationalsozialistischen Herrschaftsregime thematisiert und festgestellt; wobei in der Regel kein analytischer Ansatz oder Anspruch verfolgt wurde. In den Fokus des Interesses rückten hierbei insbesondere der italienische Faschismus ${ }^{635}$ und die spanische Diktatur unter General Franco. ${ }^{636}$ Mit Blick auf die vergleichende Auseinandersetzung mit dem Nationalsozialismus wurden dabei die qualitativen Unterschiede sowohl zwischen den drei Diktatoren Hitler, Mussolini und Franco als auch in den Bereichen der Innen- und Außenpolitik, den spezifischen Herrschaftsmethoden sowie im Kontext von Ideologie und Terror zur Sprache gebracht und hervorgehoben. Anders gesagt und bezogen auf das "Mussolini-Regime« hieß das: Der italienische Faschismus war nach Meinung von Bernhard Wall - der hier stellvertretend für einen Großteil der Autoren des Monat stehen soll - im Vergleich zum deutschen Nationalsozialismus eine »recht tolerante und umgängliche Bewegung « ${ }^{637}$ Abgesehen von den Beiträgen, in denen die einzelnen Autoren bei der vergleichenden Beschreibung und Analyse der Geschichte des >Dritten Reiches` und des Sowjetkommunismus auch wie noch zu sehen sein wird - implizit auf die Vorgeschichte der beiden Herrschaftssysteme eingingen, sondierte zum Beispiel der jüdische Historiker und Nationalismusforscher Hans Kohn in seiner Veröffentlichung Geschichte und Politik (H. 45) explizit das gesellschaftsgeschichtliche Feld des 19. Jahrhunderts. ${ }^{638}$ Seiner Auffassung nach

635 Siehe zur Geschichte des italienischen Faschismus besonderes: Ignazio Silone, Eine Anthologie aus seinem Schaffen, in: Der Monat 1 (1949), H. 10, S. 49-89 (mit der Einführung von Ceorge Woodcock, Persönlichkeit und Werk, S. 49-57), und in diesem Zusammenhang in erster Linie den Beitrag Die Auserwählten. Ein Beitrag zur Phänomenologie des Diktators, S. 77-84; hierbei handelte es sich um einen Auszug aus dem 1938 erschienenen Buch Die Schule der Diktatoren, das sich um eine satirische Auseinandersetzung über Herkunft, Wesen und Bedeutung des sogenannten Diktators handelte, mit Blick auf den Faschismus geschrieben wurde und nicht zuletzt den italienischen »Duce« Benito Mussolini fokussierte. Siehe zudem: Carlo Levi, Italien ohne Mussolini, in: Der Monat 1 (1949), H. 6, S. 25-32; $\mathrm{H}$ [ugh] R. Trevor-Roper, Ciano und Mussolini. Aufklärung und neue Mythenbildung, in: Der Monat 2 (1949), H. 13, S. 40-48; Nicola Chiaromonte, Der Bauer Silone, in: Der Monat 5 (1953), H. 52, S. 439-441 (Rezension); Luigi Barzini, Brief aus Rom: Die Faszination des Fremden. Anatomie des »schlechten« Italieners, in: Der Monat 8 (1956), H. 89, S. 45-49.

636 Siehe zur Geschichte des»Franco-Regimes«: Arturo Barea, Aus dem alten Madrid. Jugenderinnerungen eines spanischen Demokraten, in: Der Monat 1 (1949), H. 6, S. 53-63, sowie William Fifield, Brief aus Madrid: Unter der Besatzung Francos, ebd., S. 64-67; Peter Schmid, Endstation: Verzweiflung. Ein Bericht aus Spanien, in: Der Monat 3 (1951), H. 33, S. 302-304; ders., Brief aus Madrid: Der bedrohte Triumphator, in: Der Monat 3 (1951), H. 34, S. 354-360; Hugh [R.] Trevor-Roper, Hitler und Franco. Warum nahm Spanien nicht am Kriege teil?, in: Der Monat 5 (1953), H. 60, S. 625-634; Valeriano Bajocapa, Brief aus Madrid: Die Petition und das blutgetränkte Hemd. Ein Bericht über die Studentenunruhen, in: Der Monat 8 (1956), H. 91, S. 22-30, sowie Jürgen Rühle, Mit den Augen des Stabsoffiziers. Zu Ludwig Renns Der Spanische Krieg, ebd., S. 73-78 (Rezension); François Bondy, Brief aus Madrid: Was kommt nach Franco?, in: Der Monat 8 (1956), H. 93, S. 33-40; Werner Orlowsky, Das Vorspiel zum Kriege. Zum zwanzigsten Jahrestag des Spanischen Bürgerkrieges, in: Der Monat 8 (1956), H. 94, S. 22-30; François Bondy, Brief aus Madrid: Die verbrauchte Diktatur, in: Der Monat 9 (1957), H. 104, S. 39-43; Udo Rukser, Die spanische Zensur, in: Der Monat 10 (1958), H. 120, S. 71-78.

637 Bernhard Wall, Brief aus Rom: Ketzerei auf der Linken. Ein Bericht über die Krise in der KP Italiens, in: Der Monat 3 (1951), H. 31, S. 35-39, hier S. 35.

638 Vgl. unter diesem Aspekt auch die generellen Ausführungen in den Beiträgen: Hans Joachim Lieber, Macht und Furcht, in: Der Monat 3 (1951), H. 35, S. 546-548 (Rezension), sowie bes. Karl 
war das 19. Jahrhundert für das Entstehen der beiden totalitären Massenbewegungen im 20. Jahrhundert mitverantwortlich. Für Kohn war das Jahr 1848 eine entscheidende Zäsur, weil nach der für ihn letzten Endes fehlgeschlagenen Revolution sowohl der Nationalismus als auch der Sozialismus zu Massenbewegungen geworden waren, die, in der »Überbetonung der Kollektivmacht über die persönliche Freiheit«, fortan in der europäischen Geschichte vor und nach dem Ersten Weltkrieg ${ }^{639}$ eine destruktive Dynamik entfalteten. Für ihn stand in diesem Zusammenhang fest: erstens, dass die spätere außenpolitische Expansionspolitik Hitlers und Stalins ohne den durch den Ersten Weltkrieg verursachten »Untergang Österreichs« nicht möglich gewesen wäre. Zweitens, dass die beiden »bewegenden Kräfte« des 19. Jahrhunderts, nämlich der nicht die politischen und persönlichen Freiheitsrechte der einzelnen Menschen zielende (nichtuniversalistische) partikularistische Nationalismus und das »Klassenbewusstsein« für den Verlauf des 20. Jahrhunderts eine entscheidende Bedeutung besaßen, da sie sich mit alten Kräften und Traditionen - einschließlich der Religion - auf eine unheilvolle Form vermischten und vor allem in Deutschland und Russland zerstörerische Energien freisetzten, weil sich in diesen beiden Ländern eine politische Kultur der Intoleranz Bahn brach. Die Deutschen und die Russen hatten, so Kohn in seinem Beitrag Geschichte und Politik,

trotz ihres romantischen oder marxistischen Historizismus wenig Achtung für die geheimnisvollen Kräfte der Geschichte, für die vernünftige Anwendung von Ausgleich und Versöhnlichkeit gezeigt. Sie haben zwischen dem Extrem der Anbetung ihrer Vergangenheit und der Vergötzung eines rationalen und technologischen Fortschritts hin- und hergeschwankt und manchmal, wie im Falle Hitlers und im Falle Stalins, diese beiden Extreme zu einer katastrophalen Synthese zu führen gesucht. ${ }^{640}$

Der ausdrückliche Vergleich zwischen dem Nationalsozialismus und dem Sowjetkommunismus stand bereits in der zweiten Ausgabe des Monat im Mittelpunkt. Im November 1948 schrieb die aus England stammende und für die Leitartikel in der Londoner Zeitschrift Economist verantwortliche Barbara Ward hierzu im Rahmen der Umfrage »Der West-Östliche Gegensatz (Drei Aspekte)« in ihrem Beitrag Ist der Krieg mit Russland unvermeidlich? ${ }^{641}$ angesichts der für »unsere Nachkriegswelt« aufdrängenden »Furcht vor einer russischen Expansion als Ursache eines Atomkrieges und vor dem Kommunismus als Zerstörer der freien Gesellschaft«:

Dietrich Bracher, Gegen die Politik der Furcht, in: Der Monat 3 (1951), H. 36, S. 661-665 (Sammelrezension).

639 Dass für einige Autoren des Monat der Erste Weltkrieg die entscheidende historische Zäsur für das Entstehen der totalitären Bewegungen war und mithin zur gemeinsamen Vorgeschichte des nationalsozialistischen und sowjetkommunistischen Herrschaftsregimes zählte, wurde bereits hervorgehoben. In der Regel wurde indes im Monat eben diese Zäsur nur generell angesprochen respektive festgestellt. Siehe exemplarisch Denis de Rougemont, Die Krankheit der Europäischen Kultur, in: Der Monat 3 (1951), H. 32, S. 115-132, der auf S. 115 zum Ausdruck brachte, dass der Erste Weltkrieg dem »ersten Weltkrieg auf die Welt verhalf, dem Regime Lenins, das wenig später Mussolini und dann Hitler als Vorbild dienen konnte

640 Hans Kohn, Geschichte und Politik, in: Der Monat 4 (1952), H. 45, S. 325-327, hier S. 327.

641 Barbara Ward, Ist der Krieg mit Russland unvermeidlich?, in: Der Monat 1 (1948), H. 2, S. 3-7; der Beitrag erschien im Rahmen der Zeitschriften-»Umfrage«: Der West-Östliche Cegensatz (Drei Aspekte). 
Wenn wir uns zunächst der Drohung einer russischen Aggression zuwenden, so müssen wir uns seit dem vergangenen Jahr allerdings die Frage stellen, ob wir es beim russischen Kommunismus nicht mit einem ebenso gewalttätigen und expansiven System zu tun haben wie beim nationalsozialistischen. Die Analogie wurde besonders deutlich, als die Kommunisten die Tschechoslowakei unter ihre Kontrolle brachten und der Vergleich mit den Ereignissen von 1938 und 1939 - der deutschen Unterwerfung der Tschechen - sich geradezu aufdrängte. Bedeuten diese Vorgänge, daß die Russen Hitler auch auf dem unausweichlichen Weg zum Kriege folgen werden?

Wenn wir die Frage, ob das russische System ebenso zwangsläufig wie das der Nationalsozialisten zum Kriege führen muß, wirklich bejahen müssen, kann der Krieg nicht mehr lange hinausgeschoben werden. Es geht jedoch aus einem Vergleich der beiden Systeme klar hervor, daß sie nicht identisch sind.

Zur Begründung ihres Urteils, wonach das nationalsozialistische und das sowjetkommunistische System nicht identisch wären, schrieb Ward in diesem Zusammenhang:

Wenn wir uns an die historischen Tatsachen halten, stellen wir fest, daß Hitler im Jahre 1933 an die Macht kam, in sechs Jahren von einer Angriffshandlung zur anderen schritt und diese Angriffshandlungen in der Cewaltsamkeit ihrer Methoden immer weiter steigerte, bis sie in dem militärischen Angriff auf Polen ihren Höhepunkt fanden. Die Kommunisten dagegen kamen im Jahre 1917 an die Macht und bekehrten sich nach dem kurzen Versuch eines Angriffskrieges gegen Polen 1920, alsbald zu einer minder aggressiven Politik, so daß sie sich weiterer Angriffe enthielten, bis Hitler 1939 ganz Europa in den Krieg stürzte. Während das nationalsozialistische Deutschland offenbar nicht ohne Krieg leben konnte, haben die Russen bewiesen, daß sie fast 20 Jahre im Frieden zu leben imstande waren.

Das ist der erste Unterschied zwischen den beiden Systemen; der zweite ergibt sich, wenn man ihre ideologische Ausrichtung untersucht. Hitlers Anschauungen waren unverhüllt militaristisch; er verherrlichte Krieg und Blutvergießen, während die Kommunisten, mögen sie auch den Clauben haben, daß sie zur Weltherrschaft bestimmt sind, den Angriffskrieg als Mittel zur Erreichung dieses Zieles keineswegs glorifizierten. In engem Zusammenhang mit diesem Wesensunterschied steht die offensichtliche Tatsache, daß Hitler ein geisteskranker Hysteriker war, während Stalin eher den Typ des verschlagenen Politikers verkörpert. Hitlers Diplomatie kannte weder Formalitäten noch Umwege. Wenn er eine Tür verschlossen fand, trat er sie einfach ein, während Stalin umkehrt und wartet, bis irgend jemand oder irgend etwas sie ihm öffnet.

Und weiter hieß es in dem Beitrag Ist der Krieg mit Rußland unvermeidlich am Ende des Abschnittes, in dem die Verfasserin die beiden totalitären Herrschaftssysteme ausdrücklich miteinander verglich:

Der entscheidende Unterschied zwischen den beiden Systemen aber wird wohl durch die Tatsache bestimmt, daß Deutschland das Problem seines >Lebensraumes` zu lösen hatte; wenn auch die Art, wie er an die Lösung dieses Problems heranging - durch Eroberung - verkehrt war, so bestand doch das Problem als solches - das Problem einer deutschen Wirtschaft, die auf einen kontinentalen Maßstab abgestellt war und auf allen Seiten durch Zollschranken eingedämmt wurde. Die deutsche Industrie war so 
leistungsfähig, daß sie ganz Europa als Markt brauchte. Solange ihr ein ihrer Kapazität entsprechendes Absatzgebiet nicht zur Verfügung stand, lag immer die Versuchung nahe, diese Ausweitung mit kriegerischen Mitteln zu versuchen. Für Rußland gibt es ein solches Problem nicht, es braucht keine Expansion, denn die Sowjetunion umfaßt ein Sechstel der Erdoberfläche, viele Teile des Landes sind noch nicht erschlossen, und nicht vier, sondern zwanzig Fünfjahrespläne werden notwendig sein, um eine wirklich ausreichende russische Industrie zu schaffen. Die Russen brauchen keinen Krieg, um sich einen ihrer industriellen Kapazität entsprechenden Absatzmarkt zu schaffen, im Gegenteil, sie müßten logischerweise den Krieg als das einzige Hindernis einer wirtschaftlichen Entwicklung fürchten. ${ }^{642}$

Ebenso wie Ward ging auch der zur Galionsfigur der antistalinistischen »radical intellectuals« avancierte Schüler des prominenten amerikanischen Philosophen John Dewey und aus dem in den Vereinigten Staaten politisch einflussreichen Kreis der New York Jewish Intellectuals stammende trotzkistische Renegat Sidney Hook ${ }^{643}$ im Rahmen derselben Umfrage in seinem Beitrag Drei Grundzüge westlichen Denkens auf Gemeinsamkeiten des Nationalsozialismus und des stalinistischen Sowjetkommunismus ein. Vor dem Hintergrund philosophisch-politischer Reflexionen zu den ideengeschichtlichen Grundlagen der westlichen Demokratien und der konkreten politischen Praxis in den westlichen Staaten im Allgemeinen und zur Tradition amerikanischer Freiheitsrechte seit der Verkündung der Bill of Rights im Jahre 1776 im Besonderen als Gegenmodell zum sowjetischen Totalitarismus und den Diktaturen von Spanien und Portugal ${ }^{644}$ - analysierte Hook das für die westlichen Demokratien bestehende zeitgenössische Gefahrenpotenzial. Für ihn bereitete der Erste Weltkrieg den Boden für Lenin, Trotzki und Stalin auf der einen Seite sowie Mussolini, Franco und Hitler auf der anderen Seite, sodass sich auch aus diesem Grund die Tradition der westlichen Demokratie in Westeuropa, so Hook, nicht fest etablieren konnte. In diesem Kontext vertrat er folgende Auffassung:

Die westliche Lebensform bedroht außerhalb ihres eigenen Bereichs keinen anderen Lebensstil, es sei denn, daß sie in die Verteidigung gedrängt wird. Dessenungeachtet ist sie ihrerseits schwer gefährdet worden, erst durch den Nationalsozialismus, jetzt durch den Sowjet-Kommunismus. Wer den Expansionstrieb der Nationalsozialisten für eine Bedrohung der Institutionen der Demokratie gehalten hat, muß mit derselben Logik und derselben Beweisführung schlußfolgern, daß der Sowjetkommunismus heute eine noch größere Gefahr für uns darstellt, weil die mögliche Opposition gegen den Totalitarismus heute infolge des Krieges viel schwächer geworden ist und weil die Sowjetregierung in den demokratischen Ländern eine sehr viel stärkere Fünfte Kolonne unterhält, als Hitler oder Franco es je für möglich gehalten hätten.

642 Ebd., S. 3 f.

643 Siehe zu Sidney Hook die biografischen Angaben der Zeitschriftenredaktion, in: Der Monat 1 (1948), H. 2, S. 109, sowie Kap. I.1.3.

644 Siehe Sidney Hook, Drei Grundzüge westlichen Denkens, in: Der Monat 1 (1948), H. 2, S. 8-17, hier S. 8-16. 
Und angesichts der zeitgenössischen Krise und möglichen innenpolitischen Maßnahmen der westlichen Staaten schrieb Hook:

Wie kann diesem furchtbaren Kreuzzug gegen alles, was in der Tradition des Westens von dauerndem Wert ist, begegnet werden? So notwendig es ist, eine soziale Ordnung aufzubauen und Ungerechtigkeiten in unseren eigenen Ländern zu beseitigen, um die Ausbreitung des Totalitarismus aus innenpolitischen Gründen zu verhindern, würde dies doch genau so wenig ausreichen, um Stalin in Schach zu halten, wie seinerzeit soziale Reformen in England und Frankreich genügt hätten, um Hitler aufzuhalten. ${ }^{645}$

Bereits in der nächsten Ausgabe (H.3) des Monat setzte sich der philosophische und politische Schriftsteller Paul Kecskemeti unter der programmatischen Überschrift Jenseits des Sozialismus mit der Untersuchung Jenseits des Kapitalismus von Paul Sering (d. i. Richard Löwenthal) auseinander. ${ }^{646}$ Vor dem Hintergrund der zeitweise sehr populären, im Laufe der Zeit allerdings auch umstrittenen, im Jahre 1941 in New York erschienenen totalitarismustheoretischen Studie The Managerial Revolution des trotzkistischen Renegaten und späteren "Neo-Machiavellisten« James Burnham war es Serings Auffassung, so Kecskemeti zu Beginn seiner Buchrezension, dass sich die Hypothese von Marx nicht bestätigt hatte, wonach der Zusammenbruch des kapitalistischen Systems automatisch den Sozialismus herbeiführen würde. Im Gegensatz dazu hatten sich für Sering indes die marxschen Prophezeiungen erfüllt - wie zum Beispiel die zunehmende Konzentration des Kapitals »in den Händen weniger«, die »Entwicklung zum Monopol«, die immer wiederkehrenden Krisen und insbesondere der »Zusammenbruch des Kapitalismus im engeren Sinne, d. h. seine Ablösung durch `Planwirtschaften« von verschiedenem Typus«. Sering zufolge hörte der kapitalistische Eigentümer auf, der »beherrschende Faktor« im Produktionsprozess zu sein und wurde - so eine zentrale Aussage in Jenseits des Kapitalismus - an den »Kommandostellen der Wirtschaft« allmählich durch die »eigentumslose[n] >Manager oder Direktoren und staatliche[n] Funktionäre ersetzt«.

Angesichts der Reflexionen Serings zur marxschen Kapitalismusanalyse und -kritik im Allgemeinen und der radikalen Kritik des ehemaligen Mitglieds der KPD an der nach einem »hierarchischen Prinzip« organisierten wirtschaftlichen Planwirtschaft im Besonderen war Kecskemeti der Meinung, dass es dem Buchautor letzten Endes darum ging, eine neue und veränderte »Fassung des Marxismus« zu entwickeln - mit dem primären Ziel, einerseits die »friedliche Einwilligung der Gesellschaft in den Sozialismus« zu erleichtern und andererseits den Sozialismus davor zu bewahren, »zu einem antidemokratischen und totalitären Regime auszuarten«. In diesem Zusammenhang lauteten die entscheidenden Passagen in der Rezension von Kecskemeti:

Wirtschaftsplanung ist unumgänglich notwendig, behauptet Sering. Aber Planung könne auf verschiedene Arten erfolgen. Sie könne kapitalistisch oder kollektivistisch gehandhabt werden, in beiden Fällen jedoch außerdem noch demokratisch oder totalitär sein. Von den vier möglichen Formen, dem demokratischen oder totalitären Kapitalismus und dem demokratischen oder totalitären Kollektivismus, verwirft Sering alle

645 Ebd., S. $16 \mathrm{f}$.

646 Paul Kecskemeti, Jenseits des Sozialismus, in: Der Monat 1 (1948), H. 3, S. 103-106 (Rezension). 
außer dem demokratischen Kollektivismus. Die beiden totalitären Formen lehnt er aus grundsätzlichen Erwägungen ab. Die demokratisch-kapitalistische Planung vom Typus des New Deal in Amerika erscheint ihm, wenn nicht aus ethischen Cründen verwerflich, so doch aus praktischen Gründen unzulänglich. Nach seiner Ansicht kann sie den absoluten Wohlstand, d. h. die Vollbeschäftigung bei dem höchsten, dem jeweiligen Stand der Technik entsprechenden Lebensstandard nicht gewährleisten. Um diesen Wohlstand zu erreichen, braucht man nur Kollektivismus als auch Demokratie einzuführen. Sering beansprucht die Bezeichnung »Sozialismus« ausschließlich für eine kollektivistische und zugleich demokratische Gesellschaft. Der sowjetische Kollektivismus kann daher nicht »sozialistisch« genannt werden, weil er nicht demokratisch ist.

Und weiter hieß es an diesem Punkt der Rezension des Buches Jenseits des Kapitalismus:

Serings Forderung nach dem demokratischen Kollektivismus soll das ursprüngliche Ziel der »völligen Befreiung « mit den neuerdings entdeckten Tatsachen auf dem Gebiete der Produktionshierarchie in Einklang bringen. Der Kollektivismus sei notwendig, um den Menschen aus der Erniedrigung der Lohnarbeit zu emanzipieren. Demokratie sei notwendig, um ihn davor zu bewahren, von der Produktionshierarchie erneut versklavt zu werden. ${ }^{647}$

Für Sering, so Kecskemeti, sei ein »Vielparteiensystem« im Rahmen der Planung zweifelsohne möglich und vor allem notwendig, damit die »Planung demokratisch « erfolgen kann. In den Augen von Sering sollten selbstverständlich die Direktoren und Fachleute hinfort im »neuen System « eine herausragende Stellung einnehmen. Gleichwohl sollte ebenjenes System demokratisch bleiben, "solange das Volk eine wirksame Kontrolle über die Direktoren ausübt und ihre Posten nicht erblich werden, d.h., solange alle dieselben Chancen haben, zu Direktorenstellungen aufzurücken« ${ }^{648}$

Nach Auffassung von Kecskemeti waren die angesprochenen Aspekte bzw. die von Sering eingenommene Perspektive überaus zweifelhaft. In seiner radikalen Kritik brachte er unter anderem zum Ausdruck, dass es eine Illusion wäre zu glauben, dass die »Abschaffung des Privateigentums « bereits eine "gemeinnützige Wirtschaft» garantiert. Denn, so Kecskemeti, wo nämlich »entgegengesetzte Interessen in Wettstreit« liegen, kann auch und vor allem die »vollkommenste Demokratie« verhindern, dass

verschiedene, mehr oder minder große Cruppen ihre strategische Stellung zur Erlangung ungerechtfertigter Vorteile ausnutzen werden. Wenn man andererseits die unterschiedlichsten Sonderinteressen am Wettstreit miteinander hindert, hat man das Einparteiensystem [Hervorh. des Verf.]. Sering zeigt keinen Ausweg aus diesem Dilemma.

Kecskemeti schrieb in seinem Rezensionsbeitrag angesichts der sich aufdrängenden Frage, ob und in welchem Ausmaße »völliger Kollektivismus und zentrale Planung« 
mit dem »demokratischen Mehrparteiensystem« vereinbar sei in diesem Zusammenhang:

Das Beispiel legt die Vermutung nahe, daß einer straffen Zentralisierung auf wirtschaftlichem Gebiet auch die Tendenz zur politischen Zentralisierung innewohnt. Sering diskutiert in seinem Kapitel über Sowjetrußland dieses Problem nicht einmal. Er verurteilt den sowjetischen Totalitarismus, läßt dabei aber den Marxschen Crundsatz außer acht, daß in erster Linie der wirtschaftliche »Unterbau« im Auge behalten werden müsse. Statt dessen läßt er sich über so vage Begriffe »Rückständigkeit« Rußlands, den mangelnden Sinn für »freie Aussprache« und das fehlende »Rechtsbewußtsein« aus.

Will Sering damit sagen, daß der Totalitarismus in Westeuropa in jedem Falle unmöglich ist, nur weil Europa einen traditionellen Clauben an freie Diskussion und persönliche Rechte besitzt? Ich denke, das Aufkommen des Nationalsozialismus in Deutschland und des Faschismus in Italien beweisen zur Genüge, daß diese Traditionen zur Abwehr des Totalitarismus nicht ausreichen. Ihr Fehlen in Rußland kann daher nicht der entscheidende Faktor sein, der den sowjetischen Totalitarismus erklärte. Sering scheint zu glauben, daß der Faschismus (ein Kapitalismus mit totalitärer Planung) die einzige totalitäre Gefahr für den Westen darstelle, während eine kollektivistische Planung sich wenigstens aller Wahrscheinlichkeit nach in demokratischen Bahnen entwickeln würde. Dieser Frage müßte jedoch erst einmal kritisch untersucht werden. ${ }^{649}$

Nachdem der ehemalige Kommunist und Verfasser der 1940 erschienenen Totalitarismusstudie The Totalitarian Enemy, Borkenau, in der Märzausgabe des Jahres 1949 (H. 6) im Zusammenhang seiner Rezension des von Buber-Neumann im selben Jahr veröffentlichten Buches Als Gefangene bei Stalin und Hitler auf die herausragende Bedeutung des autobiografischen Erfahrungsberichtes hinwies, weil nämlich hiermit zum »ersten Mal« die kommunistische und nationalsozialistische Geheimpolizei verglichen werden konnten, konstatierte Borkenau, dass das Buch einen wichtigen Beitrag zum »vergleichenden Verständnis des politischen Terrors« darstellen würde. ${ }^{650}$ Zudem stellte der Rezensent fest, dass die Veröffentlichung mit »unerhörter Deutlichkeit« sowohl den Unterschied als auch die Verwandtschaft des deutschen und des sowjetischen Terrorsystems zum Vorschein brachte. "Den Sowjets«, so Borkenau mit Blick auf den grundsätzlichen Charakter des Terrors in den beiden totalitären Herrschaftssystemen, "geht es nicht darum, den einzelnen Menschen zu quälen. Für sie steht ohnehin fest: das Individuum ist nur ein Nichts. Wenn sie foltern, so nur zum Zwecke der Erpressung von Geständnissen.« ${ }^{651}$

649 Ebd. Siehe hierzu auch die ausführliche Erwiderung in Form eines Leserbriefes: Paul Sering (d. i. Richard Löwenthal), Planung und Freiheit, in: Der Monat 1 (1949), H. 5, S. 106-109; hier betonte Sering explizit, dass seiner Auffassung nach wirtschaftliche Planung mit »persönlicher und politischer Freiheit« vereinbar sei, und grenzte sich in diesem Kontext auch und vor allem von den sogenannten rückwärtsgewandten Utopisten des wirtschaftlichen Liberalismus, namentlich von Friedrich Hayek und Wilhelm Röpke, ab. Zudem ging Sering u. a. auf Seite 107 auf die Genesis und Entwicklung des totalitären Einparteienstaates in der Sowjetunion ein.

650 Franz Borkenau, Zwischen Rot und Braun, in: Der Monat 1 (1949), H. 6, S. 95-97, hier S. 95 (Rezension). 651 Ebd., S. 96. 
Nachdem Borkenau in seiner Rezension des Buches von Buber-Neumann einen weiteren ausdrücklichen Vergleich zwischen dem nationalsozialistischen und stalinistischen Terror zog - indes mit dem Fokus auf die deutschen und sowjetischen Konzentrationslager ${ }^{652}$ - und in der nächsten Ausgabe der Mitherausgeber des Monat, Jaesrich, in seinem Beitrag über die Kunst- bzw. Kulturpolitik in der geteilten Stadt Berlin einging und hierbei einen ausdrücklichen Vergleich zwischen den beiden totalitären Parteien NSDAP und SED zog, ${ }^{653}$ war es kein Geringerer als Aron, der im Juni 1949 im Doppelheft 8/9 den Nationalsozialismus mit dem Stalinismus verglich. Im Rahmen des aus aktuellem Anlass vom Monat organisierten Symposiums zum Thema »Erwacht Deutschland schon wieder? Der neue deutsche Nationalismus und seine Gefahren ${ }^{654}$ schrieb der französische Soziologe, Philosoph und politische Publizist angesichts des kurz zuvor ausgebrochenen Kalten Krieges und des in vier Zonen aufgeteilten Deutschland der Nachkriegszeit:

Wenigstens in einer Besatzungszone Deutschlands sind bald nach Kriegsende die Konzentrationslager wieder eingerichtet worden. Es mag sein, daß man dort nicht die Ausrottungsmaßnahmen anwendet, die während der letzten Jahre der SS-Herrschaft im Schwange waren. Doch wie wollte man angesichts dieser Fakten [u. a. Vertreibung der»Sudeten-Deutschen«sowie die sogenannte»Annektion«Ostpreußens, Pommerns und Schlesiens durch die Rote Armee] vermeiden, daß die Deutschen trotz allem den Schluß ziehen, daß offenbar nicht eine einzige Nation das Monopol der technisierten Grausamkeit besitzt? ${ }^{655}$

In derselben Ausgabe des Monat verglich der am Genfer Institut Universitaire des Hautes Etudes Internationales lehrende, international bekannte Theoretiker und Experte für Nationalökonomie und leidenschaftliche Vertreter eines wirtschaftlichen Liberalismus, Wilhelm Röpke, die beiden totalitären Regierungen des Nationalsozialismus und des Stalinismus. In einem zuerst in der Schweizer Zeitschrift Humanitas veröffentlichten »offenen Brief« schrieb er in dem im Monat als Leserbrief abgedruckten

652 Darauf gehe ich in Kapitel IV.3.3 ein.

653 Hellmut Jaesrich, Der Schnitt durch die Kunst. Die Geschichte eines Berliner Boykotts, in: Der Monat 1 (1949), H. 7, S. 90-97. Hier hieß es vor dem Hintergrund eines Cedankenexperiments des Verfassers, der nämlich die zeitgenössische politische und kulturpolitische Situation der Frontstadt Berlin zurückprojizierte in das Jahr 1933 nach der Übernahme der »Regierungsgewalt« durch »eine Partei mit totalitärem Anspruch in Berlin« und dem danach in Gang gekommenen Terror - «Kristallnacht und Synagogenbrände, die Erschießung, Verschleppung und willkürliche Vernichtung Unschuldiger« (S. 90) - auf S. 91: »Nun, ein solches Berlin gibt es jetzt, wenn man kühn genug ist, Nationalsozialismus und Bolschewismus und die selbst erworbene Stoßkraft der NSDAP mit der von der Besatzungsmacht erborgten der SED zu vergleichen. Man mag gegen diese Gleichsetzung Bedenken haben, auf die wir zurückkommen wollen. Hier genüge die leicht zu stützende Behauptung, daß die Gemeinsamkeiten - der Gebrauch des Terrors, die Lähmung der freien Meinungsäußerung und die generelle Geistfeindlichkeit - vor den Unterschieden überwiegen.«

654 Erwacht Deutschland schon wieder? Der neue deutsche Nationalismus und seine Cefahren«, in: Der Monat 1 (1949), H. 8/9, S. 3-64. Mit Beiträgen u. a. von Walter L. Dorn, Richard H. S. Crossmann, Dolf Sternberger, Paul Sering (d. i. Richard Löwenthal), Manuel Gasser, A. J. P. Taylor, Peter de Mendelssohn, Wilhelm Roepke, Erik Reger, Eugen Kogon, Franz Borkenau.

655 Raymond Aron, Für ein europäisches Deutschland, in: Ebd., S. 11-15, hier S. 12. 
Beitrag Rußland und Abendland - vor dem Hintergrund der ausdrücklichen Unterscheidung zwischen Russland als Kulturnation und seiner Bevölkerung sowie dem eigentlichen Problem, das Röpke im Bolschewismus ausmachte, weil nämlich dieser sogenannte pseudoreligiöse "Islam, dessen Mekka sich nun einmal in Moskau« befand«, der seiner Auffassung nach die "geistigen Grundlagen des Abendlandes« bedrohte:

Daß diese Gefahr der früheren nationalsozialistischen verwandt ist, liegt auf der Hand. Aber hier gibt es einen Unterschied [...]. Als geistige Cefahr ist der Bolschewismus weit furchtbarer, als es der Nationalsozialismus je gewesen ist, und zwar wegen seines universellen und rationalistischen Charakters. Man konnte keinen Hottentotten zum Nationalsozialisten machen, weil man ihn unmöglich von dieser wirren Theorie des »Herrenvolkes« überzeugen konnte; aber man kann ihn im Handumdrehen zum Kommunisten machen [...]. Gerade weil der Bolschewismus als ein rationalistisch-universeller Islam einen verführerischen Appell an die geistigen oder charakterlichen Schwächen aller Menschen (oder an ihr schlechtes Cewissen) richtet, verfügt er über eine »fünfte Kolonne«, mit der verglichen, diejenige des Nationalsozialismus (oder Faschismus) komisch erscheint. ${ }^{656}$

In den beiden letzten Ausgaben des ersten Jahrganges des Monat, im August und September 1949 (H. 11 und 12), erschien von dem in Paris lebenden italienischen antifaschistischen Emigranten A. Rossi (d. i. Angela Tasca) die deutsche Übersetzung der in Frankreich veröffentlichten »kleinen Studie« zum Hitler-Stalin-Pakt. In der unter dem Titel Zwei Jahre deutsch-sowjetisches Bündnis ${ }^{657}$ (Teil 1) und Zwei Jahre deutsch-sowjetische Freundschaft ${ }^{658}$ (Teil 2) abgedruckten Studie untersuchte Rossi ${ }^{659}$ in erster Linie auf der Basis der Nürnberger Prozessdokumente ${ }^{660}$ die politisch-historische Genese

656 Wilhelm Röpke, Rußland und das Abendland, in: Der Monat 1 (1949), H. 8/9, S. 157.

657 A. Rossi (d. i. Angela Tasca), Eine historische Rekonstruktion: Zwei Jahre deutsch-sowjetisches Bündnis (August 1939-Juni 1941), in: Der Monat 1 (1949), H. 11, S. 74-98.

658 Ders., Zwei Jahre deutsch-sowjetische Freundschaft (Fortsetzung und Schluß), in: Der Monat 1 (1949), H. 12, S. 40-55.

659 Zum Autor hieß es in Der Monat 1 (1949), H. 11, S. 128: »Hinter dem Namen A. Rossi verbirgt sich ein in Paris lebender italienischer Emigrant und leidenschaftlicher Bekämpfer Mussolinis, der 1938 mit einer historischen Darstellung der Anfänge des Faschismus, die zugleich in französischer und englischer Sprache erschien, berechtigtes Aufsehen erregte. Noch bedeutsamer ist der erste Teil eines auf drei Bände angelegten Werkes `Crise française, crise mondiale`, der im vorigen Jahr erschien und sich >Physiologie du parti communiste français benennt [...]. Dieser Band behandelt aufgrund der genauesten und intimsten Kenntnisse vor allem das Verhalten der Kommunistischen Partei Frankreichs während der ersten Jahre des vergangenen Krieges, während die beiden folgenden sich mit der französischen Widerstandsbewegung und mit der Haltung Sowjetrußlands gegenüber Europa beschäftigen sollen. Die in diesem Zusammenhang erforderliche Auswertung des amerikanischen Weißbuches und vieler anderer gedruckter und ungedruckter Dokumente über die gleiche Frage hat Rossi veranlaßt, zu diesem Thema eine kleinere Studie zu schreiben, die bei Artheme Fayard in Paris als Buch erschienen ist und der unser Beitrag entnommen ist."

660 Zu den Dokumenten des Nürnberger Hauptkriegsverbrecherprozesses, auf die sich der Autor in seinem insgesamt 118 Fußnoten umfassenden ersten Teil seiner historischen Studie bezog, schrieb A. Rossi, Eine historische Rekonstruktion: Zwei Jahre deutsch-sowjetisches Bündnis (August 1939-Juni 1941), in: Der Monat 1 (1949), H. 11, auf S. 74 zu Beginn seines Beitrages: »Nach dem Zusammenbruch 
und Entwicklung der für die internationale Staatenwelt eine absolute Sensation darstellenden und Verwirrung und Bestürzung hervorrufenden diplomatischen Beziehungen sowie vertraglichen Abmachungen der beiden politisch-ideologischen Todfeinder des deutschen Nationalsozialismus und des sowjetischen Kommunismus im Zeitraum August 1939 bis Juni 1941. Die skleine Studie< stellte im Zusammenhang mit der Auseinandersetzung des historisch-politischen Bündnisses zwischen dem deutschen Staat unter Hitler und dem sowjetischen Staat unter Stalin im Monat die grundlegendste Veröffentlichung dar ${ }^{661}$ und soll nicht zuletzt aufgrund der substanziellen Beschreibung und Analyse von Rossi sowie des wissenschaftlichen Charakters der Untersuchung im Folgenden ausführlich referiert werden.

Vor dem Hintergrund seiner Ausführungen der deutsch-sowjetischen außenpolitischen Beziehungen in den 1920er-Jahren, die sicherlich mit dem »Seeckt-Plan ${ }^{662}$ und dem »Rapollo-Vertrag “ ${ }^{663}$ ihren Höhepunkt fanden, stellte Rossi fest, dass »von Hitlers Seite und zwar ausschließlich von Hitler« die »ersten Gesten der Feindseligkeiten« kamen. ${ }^{664}$ Indes: Mit Blick auf den konkreten Zeitraum des ersten Teils seiner Studie, der zum einen die »Vorbereitung des Abkommens«, d.h. die Monate März bis Juni 1939, und zum anderen die entscheidenden Wochen des August 1939 thematisierte und bis zum Abend des 31. August reichte - dem Tag der Ratifizierung des sogenannten Paktes durch den Obersten Sowjet; mithin endete dieser Teil am Vorabend des Überfalls der deutschen Wehrmacht auf Polen -, war es Rossis Auffassung nach der zu allem entschlossene Kremlchef, der die »Fäden zog« und die diplomatischen Geschicke nicht nur immer wieder in Gang brachte, sondern letzten Endes auch diktierte. Genauer gesagt: Hinsichtlich des in der Nacht vom 19. zum 20. August 1939 in Berlin unterzeich-

Deutschlands sind viele Tonnen von Archiv-Akten in die Hände der Alliierten gefallen. Ein Teil der Dokumente fand beim Nürnberger Prozeß Verwendung, die übrigen wurden für spätere Publikationen zurückgestellt. Die ersten Auswertungs- und Klassifizierungsarbeiten sind jedoch schon auf deutschem Boden vorgenommen worden, wenigstens was das von den amerikanischen und britischen Besatzungsbehörden aufgefundene Material anlangt, das zunächst photografiert und dann in großen Zügen gesichtet wurde. Dank begrüßenswerten Initiativen der amerikanischen Regierung sind jetzt vor allem auch die Schriftstücke über die deutsch-sowjetischen Beziehungen vom März 1939 bis Juni 1941 bekannt geworden. Die Veröffentlichung dieser Dokumente ermöglicht es den Historikern, endlich aus der Sackgasse herauszufinden, in die sie angesichts des Schweigens der offiziellen Stellen und der Einseitigkeit aller bisherigen Darstellungen der fraglichen Vorgänge geraten waren.«

661 Siehe hierzu auch die entsprechenden, indes indirekten Ausführungen zum Hitler-Stalin-Pakt in folgenden Beiträgen: Herbert Lüthy, Salto mortale der Dialektik, in: Der Monat 3 (1951), H. 31, S. 89-97 (Rezension); F[ritz] R[ené] Allemann, Die Rußlandpolitik des Dritten Reiches, in: Der Monat 3 (1951), H. 32, S. 199-202 (Rezension) sowie Franz Borkenau, Barbarische Freundschaft, in: Der Monat 4 (1952), H. 46, S. 414-417 (Rezension).

662 Vgl. hierzu grundsätzlich: Der Seeckt-Plan, in: Der Monat 1 (1948), H. 2, S. 42-58; mit folgenden Beiträgen: Julius Epstein, Aus unveröffentlichten Dokumenten. Neues Tatsachenmaterial über die geheime Zusammenarbeit zwischen Reichswehr und Sowjet-Armee, Eugen Fischer-Baling, Politik und Kriegsromantik und M[elvin] ]. L[asky], Seeckt, Stalin und Europa.

663 Vgl. hierzu Fritz René Allemann, Rapallo - Mythos und Wirklichkeit, in: Der Monat 14 (1962), H. 163, S. 5-12; der Beitrag liegt indes außerhalb des in diesem Teil der vorliegenden Arbeit zugrunde liegenden Untersuchungszeitraumes.

664 A. Rossi, Eine historische Rekonstruktion: Zwei Jahre deutsch-sowjetisches Bündnis (August 1939Juni 1941), in: Der Monat 1 (1949), H. 11, S. 74. 
neten Wirtschaftsabkommens zwischen der deutschen und sowjetischen Regierung, dem in den Abendstunden des 23. August in Moskau zwischen den beiden Außenministern, Joachim von Ribbentrop und Wjatscheslaw M. Molotow, im Beisein von Stalin unterzeichneten deutsch-sowjetischen Nichtangriffspakts - der über das zwischenstaatliche Nichtangriffsversprechen hinausgehend eine absolute Neutralität festlegte - und dem $» G e h e i m e n$ Zusatzprotokoll $\aleph^{665}$ vermittelten die Ausführungen des italienischen Historikers explizit und implizit den Eindruck, dass in erster Linie Stalin der zentrale politische Akteur war und mehr oder weniger das Handlungsgeschehen bestimmte, und dem außerdem der politische »Mehrwert « an der sogenannten Beute zufiel. Infolgedessen sah Rossi Stalins »kongeniale[n] Partner« Hitler im Grunde genommen in einer eher passiven Rolle, der sämtlichen politischen Forderungen und Bedingungen des Kremlchefs bereitwillig zustimmte, um sein zentrales Ziel zu erreichen, das der Autor neben dem Gewinn von »Lebensraum im Osten« im »Blitzkrieg« gegen Polen sah. ${ }^{666}$

Im zweiten Teil seines Beitrages Zwei Jahre deutsch-sowjetisches Bündnis in Heft 11 thematisierte Rossi ausschließlich die politischen und diplomatischen Entwicklungen nach dem Überfall der deutschen Wehrmacht auf Polen am Morgen des 1. September 1939. In diesem Zusammenhang streifte er die strategischen Überlegungen Hitlers und somit den für das deutsche Regime im Grunde genommen existenziellen Plan, den »Zweifrontenkrieg« zu vermeiden. Für Rossi kam der Angriff auf Polen für Stalin nicht überraschend. ${ }^{667}$ Am 17. September griff die Rote Armee direkt in das Kriegsgeschehen ein und marschierte in den östlichen Teil Polens ein. Am 19. September ließ Stalin der deutschen Regierung durch Molotow schriftlich mitteilen, dass er seine »ursprüngliche Absicht, ein Restgebilde des polnischen Staates bestehen zu lassen, aufgegeben « hatte und jetzt eine Teilung Polens entlang der Linie Pissa-NarewWeichsel-San favorisierte, und zwar so, »wie sie am 23. August vereinbart worden « war. ${ }^{668}$ Für Rossi bestanden die historisch-politischen Implikationen der Aufteilung Polens unter anderem darin, dass die drei baltischen Staaten unter die Kontrolle der Sowjetunion fielen und die »Provinzen mit rein polnischer Bevölkerung« in den drei baltischen Staaten, deren »Assimilierung« aus der Sicht Moskaus »schwierig gewesen wäre«, im Folgenden in die Hände der Deutschen fielen. Es war dem Kremlchef »herzlich gleichgültig«, »ob ein paar Millionen Polen den Nationalsozialisten ausgeliefert wurden ${ }^{669}$

Und weiter hieß es:

665 Das Geheime Zusatzprotokoll enthielt die Vereinbarung zwischen den beiden imperialen Mächten, dass für»den Fall einer territorial-politischen Umgestaltung der zum polnischen Staate gehörenden Gebiete« eine konkrete Aufteilung ihrer Interessensphären vorsah, demzufolge Polen entlang der Flüsse Narew, Weichsel und San aufgeteilt werden sollte; zudem sicherte sich die sowjetische Seite »in Erwartung der Besetzung jetzt schon die Kontrolle über Finnland, Estland und Litauen, über Ostpolen [...] sowie über Bessarbien.«(Ebd., S. 87 mit dem genauen Wortlaut des Ceheimen Zusatzprotokolls)

666 Siehe hierzu den gesamten ersten Teil, in: Ebd., S. 74-88.

667 Ebd., S. 89.

668 Ebd., S. 95.

669 Ebd., S. 96. 
Ein nüchtern urteilender Historiker muß zugeben, daß das »Generalgouvernement Polen« so wie es durch den Erlaß Hitlers vom 8. Oktober zehn Tage nach Abschluß der Moskauer Abkommen ins Leben gerufen wurde, das unmittelbare Resultat der Politik und der Vorschläge Stalins war. Die Lage Polens hätte sich weniger hoffnungslos gestaltet, wenn ceteris paribus, Hitler nicht von Stalin zum Handeln gezwungen worden wäre, wobei ihm dieser gerade den Teil des polnischen Territoriums mit den Millionen jüdischer Einwohner auslieferte, die in der Folge fast alle vernichtet wurden ${ }^{670}$

Im zweiten Teil seiner Studie zu dem deutsch-sowjetischen Bündnis (H.12) ${ }^{671}$ untersuchte Rossi den Zeitraum nach Beginn des Zweiten Weltkrieges bis Mitte November 1940. Hier beleuchtete er das alles andere als einträchtige Verhältnis zwischen der deutschen und der sowjetischen Regierung unmittelbar nach der Unterzeichnung des Bündnisses im August und September 1939. Vor dem Hintergrund seiner zu Beginn formulierten These, dass sowohl Hitler als auch Stalin entschlossen waren, den »Pakt bei der ersten Gelegenheit zu brechen «, ${ }^{672}$ kam er im Verlauf seiner Ausführungen immer wieder zu der Ansicht, dass es bei der engen Zusammenarbeit der beiden späteren >Todfeinde letzten Endes der Kremlchef war, der der eigentlich >böse Bube<war, und zwar aus folgenden Gründen: Erstens unterstützte Stalin den nationalsozialistischen Machthaber nicht nur direkt, sondern auch dadurch, dass er »auf die Gegner Deutschlands indirekt Druck « ausübte und zudem hierbei »die deutsche Politik auch moralisch « rechtfertigte. ${ }^{673}$ Zweitens erwies sich schlussendlich die deutsche Regierung in diesem Zeitraum gegenüber Moskau als streuer Vertragspartner; wobei sich diese Treue freilich aus dem Umstand ergab, das primäre außenpolitische Ziel Hitlers, nämlich bei der nationalsozialistischen »Neuordnung Europas« und dem militärischen Sieg über Frankreich einen »Zweifrontenkrieg« zu vermeiden, nicht zu gefährden. Drittens war es im Zusammenhang mit Hitlers strategischen Überlegungen, die Sowjetunion in den existierenden sogenannten Dreimächtepakt - bestehend aus Deutschland, Italien und Japan - einzubeziehen, ausschließlich Stalin, der immer neue Forderungen stellte, indem er nämlich »eine neuerliche Abgrenzung der jeweiligen Interessensphären « von der deutschen Regierung forderte. ${ }^{674}$

Letzten Endes war es für Rossi auch Moskau, das im Kontext des sogenannten Programms des »neuen sowjetischen Imperialismus« Forderungen auf Grundlage der deutsch-sowjetischen Abmachungen stellte - zum Beispiel in Bezug auf Finnland, die

670 Ebd., S. 97. - Im Anschluss an das Zitat erfolgte der Hinweis, dass am 28. September 1939 der „Deutsch-Sowjetische Grenz- und Freundschaftsvertrag « zwischen Molotow und dem deutschen Botschafter in Moskau, Fritz Dietlof Graf von der Schulenburg, unterzeichnet wurde, der die territorialen Fragen im Hinblick auf die polnische Grenze regelte. Zudem wies A. Rossi in diesem Zusammenhang darauf hin, dass hinsichtlich »Litauens und des Gebietes von Suwalki « und die damit verbundenen »Modifikationen des Geheimprotokolls vom 23. August in einem neuen Geheimprotokoll ihren Niederschlag [fanden], das am Morgen des 29. September unterzeichnet wurde, jedoch das Datum des Vortages trug«; zum genauen Inhalt der beiden sogenannten Protokolle siehe ebd., S. $97 \mathrm{f}$.

671 A. Rossi, Zwei Jahre deutsch-sowjetische Freundschaft (Fortsetzung und Schluß), in: Der Monat 1 (1949), H. 12, S. 40-55.

672 Ebd., S. 40.

673 Ebd., S. 43.

674 Ebd., S. 53. 
zum einen zu den beiden von Ribbentrop am 13. November 1940 vorgeschlagenen »Geheimprotokollen« führte und zum anderen zu den ausdrücklich auf »Verlangen der sowjetischen Regierung " gemachten Absprachen in den drei weiteren Protokollen -, in denen sich Deutschland verpflichtete, »seine eigenen Truppen unverzüglich aus Finnland zurückzuziehen", und außerdem bestätigte, dass sich Bulgarien innerhalb der sowjetischen Sicherheitszone befände und dass »aus diesem Grunde ein gegenseitiger Beistandspakt zwischen der UdSSR und Bulgarien notwendig sei, der jedoch keinerlei Einfluß auf das innere Regime und die Souveränität Bulgariens haben würde«. ${ }^{675}$

In diesem Zusammenhang schrieb Rossi im vorletzten Absatz seines Beitrages Zwei Jahre deutsch-sowjetische Freundschaft:

Mit diesem offiziellen Exposé umriß die Sowjetunion auf das genaueste die Bedingungen, unter denen sie bereit war, sich dem zwei Monate zuvor von Deutschland, Italien und Japan in Berlin unterzeichneten Pakt anzuschließen. Die sowjetischen Gegenvorschläge sollten von Deutschland nie beantwortet werden, obwohl der Kreml wiederholt um eine Antwort bat. ${ }^{676}$

Nachdem Rossi im Schlussabsatz darauf hinwies, dass eine von Hitler am 12. November 1940 erlassene und von Jodl (Chef des Wehrmachtführungsstabes) unterzeichnete sogenannte Direktive 18 zur militärischen Lage neben Anweisungen »für die weitere Kriegsführung gegen England« die Mitteilung enthielt, dass die Verlegung von deutschen Truppen in die Ostgebiete fortgesetzt werde, und dass »die Reichsregierung zugleich die augenblickliche Haltung Sowjetrußlands in Erfahrung zu bringen suche« hierzu sollte die anstehende Unterhaltung mit Molotow dienen -, schrieb er am Ende seiner ’kleinen Studieく:

Das Ergebnis dieser Gespräche war indessen nicht dazu angetan, Hitlers Besorgnisse abzuschwächen. Am 13. November erklärte er Göring gegenüber, die sowjetischen Forderungen müßten abgelehnt werden und die Vorschläge des Kremls in bezug auf Südosteuropa seien unakzeptabel. Er erblickte hierin, wie auch in den sowjetischen Forderungen nach absoluter Handlungsfreiheit in Finnland, einen großen Einkreisungsversuch gegen Deutschland und war entschlossen, ihn zu verhindern. Wie der damalige deutsche Botschafter in der Türkei, von Papen, es formulierte, hatte Deutschland in diesem Augenblick den Krieg verloren, denn von nun an war die bewaffnete Auseinandersetzung mit Sowjetrußland unvermeidlich. ${ }^{677}$

Nach dieser politisch-wissenschaftlichen Untersuchung zum Hitler-Stalin-Pakt erschien kurz darauf im Januar 1950 (H. 16) der erste von zwei Teilen eines Vorabdruckes aus dem in den Vereinigten Staaten ein Jahr zuvor vom US-amerikanischen Historiker, Publizisten und Regierungsberater Arthur M. Schlesinger jr. ${ }^{678}$ unter dem Titel The Vi-

675 Ebd., S. 55 .

676 Ebd.

677 Ebd.

678 Beim redaktionellen Hinweis zu dem Beitrag: Arthur M. Schlesinger jr., Brief aus Washington: Die transatlantische Gemeinschaft, in: Der Monat 1 (1949), H. 4, S. 11-19, hieß es auf S. 11 zum Autor: »Arthur M. Schlesinger jun. ist trotz seiner Jugend einer der bekanntesten amerikanischen Historiker 
tal Center. The Politics of Freedom veröffentlichten Buches. ${ }^{679}$ Da es sich um eine wichtige Totalitarismusstudie und um einen grundlegenden Text zum Totalitarismusphänomen im Monat handelte, der in eine substanzielle vergleichende Analyse der Geschichte des NS-Staates und des sowjetischen Staates mündete, soll er im Folgenden ausführlich referiert werden.

In den einleitenden Worten zum ersten Teil der beiden Beiträge brachte die Zeitschriftenredaktion unter anderem zum Ausdruck, dass angesichts der unmittelbar zurückliegenden Jahrzehnte der geschichtliche Nachweis geliefert wurde, dass zweifelsohne sowohl die politische Linke als auch die politische Rechte zum »Scheitern verdammt war«. Denn, so die redaktionelle Auffassung, ebendiese Jahrzehnte hatten die »Krise und Auflösung« der bürgerlichen Vorkriegsgesellschaft in England und Frankreich und die »Konvulsionen des Faschismus in Italien und Deutschland« enthalten, dazu das "große Experiment des Bolschewismus, dessen grausame Entartung dem Lernbegierigen neues Anschauungsmaterial geliefert hat«. Hieraus folgte für die Redaktion des Monat um Lasky, dass die "große schillernde Seifenblase des Optimismus" des 19. Jahrhunderts »endgültig zerplatzt« war, sodass für sie die Begriffe »Freiheit« und »Demokratie«, denen seit dem Zeitalter der Aufklärung die Vorstellung innewohnte, dass die Spezies Mensch sich permanent »vervollkommnen« und infolgedessen an »Einsicht und Selbstlosigkeit« zunehmen könnte, zu Beginn des Jahres 1950 bei ihrem »offiziösen Gebrauch einen immer hohleren Klang« bekamen. Und in diesem Zusammenhang schrieb die Redaktion des Monat im Vorwort:

Gerade das Wissen um die sowjetische Entwicklung hat, unmittelbar nach dem Erlebnis des Faschismus und Nationalsozialismus, notgedrungen Zweifel an der perfektiblen Natur des Menschen hervorgerufen. Sie hat gezeigt, daß die unkontrollierte Cewalt in jeder Hand Fürchterliches hervorruft. Sie hat viel dazu beigetragen, in unserem politischen Denken die Angst zur alles beherrschenden Dimension zu machen. ${ }^{680}$

Am Anfang seines Beitrages Politik im Zeitalter der Angst formulierte Schlesinger jr. seine zentrale These, wonach nämlich der »westliche Mensch« in der Mitte des 20. Jahr-

und Publizisten. Von seinem Lehrstuhl an der Harvard University beurlaubt, verbrachte er einige Monate im Stabe der ECA in Paris."

679 Arthur M. Schlesinger jr., Politik im Zeitalter der Angst, in: Der Monat 2 (1950), H. 16, S. 339-352 (Teil I) sowie (Teil II) H. 19 (1950), S. 68-75.

680 Alle Zitate im redaktionellen Vorwort in dem ersten Teil des Beitrages Arthur M. Schlesinger jr., Politik im Zeitalter der Angst, in: Der Monat 2 (1950), H. 16, S. 339. An dieser Stelle hieß es auf S. 339 f. weiter: »Wir veröffentlichen im folgenden die wesentlichsten Abschnitte aus Schlesingers neuem Buch, in dem er eine neue Ausgangsposition zu gewinnen sucht, die den bisherigen Fehlern etwa des Rechtskonservatismus oder andererseits einer fortschrittlich-liberalen Linken aus dem Wege zu gehen sucht. Nach seiner Auffassung, für die er reichliche Belege liefert, haben sich die Totalitarismen von rechts und von links über einem dunklen Meer von Tyrannei und Terror die Hand gereicht. Es gilt deshalb, von den äußersten Flügeln zur Mitte zurückzukehren, zu einer breiten demokratischen Front, die alle Elemente von der nicht-kommunistischen Linken bis zur nicht-faschistischen Rechten vereinigt. Kann das gelingen? Gibt es ein solches svitales Zentrum ? Können wir eine Cesellschaft errichten, in der die Menschen frei und glücklich sind, oder stehen dem tief verankerte, in der Psyche des Einzelnen und der Masse begründete Hindernisse im Wege? Nur mit der Kühle eines unbestechlichen Intellekts wird auf diese Fragen zu antworten sein. Nur mit der Glut eines neugewonnenen politischen und ethischen Wollens wird das Ziel zu erreichen sein.« 
hunderts »angespannt, unsicher, ziellos « wäre und die zeitgenössische Epoche als eine »time of troubles«, als ebenjenes Zeitalter der Angst apostrophiert werden könne. Für ihn stand fest, dass die »Grundlagen unserer Zivilisation, unserer Sicherheit« weggebrochen waren und »vertraute Vorstellungen und Einrichtungen« den Menschen als auch den »Völkern« keinen Halt mehr gaben. »Einzig die USA«, so Schlesinger jr., »haben noch stoßdämpfende Faktoren zwischen sich und den Ängsten unseres Zeitalters: Faktoren, die in der Zeit, in der Entfernung, im natürlichen Wohlstand, in einer der Nation eigenen Findigkeit und in einem zähen, altüberlieferten Optimismus begründet liegen. ${ }^{681}$

Bevor gezeigt wird, wie Schlesinger jr. den Nationalsozialismus mit dem Sowjetkommunismus verglich, müssen indes zuerst seine Reflexionen im Hinblick auf die für die Vereinigten Staaten von Amerika charakteristische »Geisteshaltung« ausführlich zusammengefasst werden. Denn nur mittels seiner komplexen Argumentationslogik zu ebendieser Geisteshaltung wird der anschließende Vergleich zwischen dem deutschen Nationalsozialismus (sowie dem italienischen Faschismus) und dem sowjetischen Kommunismus verständlich. In den Augen Schlesingers jr. war für diese Geisteshaltung, dessen Genesis und Entwicklung quasi mit der modernen (kapitalistischen) Industriegesellschaft koinzidierte, charakteristisch, dass er den Glauben an den Erfolg zur »Religion« machte. Seiner Meinung nach war es gerade für die Vereinigten Staaten sehr schwer, sich auf die grundsätzlich andere Geisteshaltung einzustellen, die Mitte des 20. Jahrhunderts bestimmend war. Das 20. Jahrhundert konnte für ihn als Zeitalter des >Umsonst< apostrophiert werden, denn: Umsonst waren nämlich der Triumph in der Wissenschaft und der Fortschritt der Technik, umsonst auch die »edelsten Hoffnungen« und die "glanzvollsten Träume«. Seiner Auffassung nach stand fest: »Was das Jahr 1900 als nahe Zukunft vor sich sah, war ein unaufhaltsam wachsendes Reich der Freiheit, der Demokratie und des Überflusses; das Jahr 1950 blickt auf Totalitarismus zurück, auf Konzentrationslager, tausendfaches Hungersterben und auf den drohenden Schatten der Atombombe."

Die für Schlesinger jr. mit Blick auf die Vereinigten Staaten als Welttragödie bezeichnete zeitgenössische politische Situation ließ sich seiner Ansicht nach mit folgenden Worten kennzeichnen: »Entweder wir oder sie; die Vereinigten Staaten oder die Sowjetunion; Kapitalismus oder Kommunismus; ist erst dieser Konflikt gelöst, so werden auch alle anderen Probleme gelöst werden. [...] Aber täuschen wir uns nicht; wir dürfen die amerikanisch-sowjetische Rivalität nicht als die Quelle der Weltnöte betrachten. ${ }^{682}$

Für Schlesinger jr. waren weder Kapitalismus noch Kommunismus die Ursache der zum damaligen Zeitpunkt aufkommenden Angst und auch nicht irgendein bestimmtes »System der Besitzverhältnisse«, sondern die gesellschaftliche Entwicklung, genauer gesagt, die »industrielle Organisation « sowie der sich durch die industrielle Entwicklung herauskristallisierende (moderne) Staat. Angesichts des auf der ganzen Welt durchlaufenen Wandels der »Lebensform« in den zurückliegenden drei Jahrhunderten und des damit korrespondierenden beschleunigten "Lebenstempos « war der amerikanische Historiker der Auffassung, dass damit eine adäquate zeitgenössische »neue Gesellschaftsstruktur absolut notwendig geworden« sei, d.h. »eine Gesell-

681 Ebd., S. 340.

682 Ebd. 
schaftsstruktur, in der das Individuum ein gewisses Maß von Selbstverwirklichung erreichen kann«. In diesem Zusammenhang schrieb er:

Dieser neuen Gesellschaftsstruktur muß gelingen, was die alten Rechtsordnungen der Familie, der Sippe, der Zunft und des Nationalstaates nicht vermocht haben. Sie muß die Probleme lösen, die durch die Beschleunigung des Zeitablaufes, die Verkürzung des Raumes und den Zuwachs an Spannungen entstanden sind. Sie muß neue Äquivalente für die Ordnungen entwickeln, die einst durch Sitte und Religion aufgestellt wurden. Die Anforderungen, die der Bau dieser neuen Cesellschaftsordnung stellt, müssen notwendigerweise die emotionellen und sittlichen Kräfte des Individuums und der Cemeinschaft auf das Äußerste anspannen.

Rückblickend kann man sagen, daß diese Anforderungen wohl zu schwer und zu belastend gewesen sind. Die Zivilisation hat sie nicht zu erfüllen vermocht, und darum wird sie heute von Angst und Furcht verzehrt. Es gelang ihr nicht, eine neue Cesellschaftsstruktur zu schaffen, und so wurde sie eher zum Opfer als zur Beherrscherin des Industrialismus. Die Befreiung des Individuums während der Renaissance und Reformation setzte die industrielle Revolution in Bewegung; in ihrem Verlauf hat der Industrialismus den Menschen neue Freiheiten und Entwicklungsmöglichkeiten gegeben. Aber letzten Endes geht seine Tendenz - eine Tendenz, die gerade in seiner technischen Natur begründet liegt - darauf hinaus, die wirtschaftlichen Beziehungen zu entpersönlichen -wie auch immer die Besitzverhältnisse sein mögen. Im Endergebnis drückt der Industrialismus das freie Individuum langsam an die Wand. ${ }^{683}$

Für den Autor stand angesichts seiner Ausführungen fest, dass die moderne Industriegesellschaft im Unterschied zu den auf "persönlichen Bindungen« beruhenden sowie von einer "persönlichen Ethik« gelenkten traditionellen Gesellschaften sowohl ebendiese Bindungen als auch demzufolge die Ethik vernichtete. Der aus diesem Umstand entstandene »neue Kodex« führte, so Schlesinger jr., zu einer »Kluft zwischen Wirtschaftspraxis und persönlicher Moral«, die sich seiner Ansicht nach zum einen extrem schnell und auf eine »beunruhigende Weise« ausweitete sowie zum anderen im »industriellen Manager« seinen Prototyp und in der Aktiengesellschaft seinen negativen organisatorischen Höhepunkt fand. Die »Unpersönlichkeit des neuen Wirtschaftssystems « hatte vor allem zur Folge, so Schlesinger jr. weiter, dass niemand die direkte Verantwortung für den »offensichtlichen und furchtbaren Preis an menschlichen Leiden zu fühlen brauchte«, den dieses Wirtschaftssystem forderte. Ein zentraler Gesichtspunkt war für den amerikanischen Historiker, dass es zweifelsohne ein »verstecktes Schuldgefühl« gab. In diesem Zusammenhang schrieb er:

Aber gerade der Mechanismus der Organisation bot Trost und Absolution. Je feiner und umfassender die Organisation wurde, desto mehr wurde sie zu dem Mittel, mit dessen Hilfe der sittlich verantwortliche Mensch seiner natürlichen Schwäche für unsittliche Handlungen nachgeben konnte. Jede Organisation litt an dieser inneren Tendenz.

Diese innere Tendenz galt nicht nur für die konkurrierenden Aktiengesellschaften, zumal in der Form des Monopols, sondern mit gewissen Einschränkungen sowohl für 
den demokratischen Staat als auch in »erschreckendem Ausmaß « für den totalitären Staat. Für Schlesinger jr. stand fest, dass die »Unpersönlichkeit des Systems« in erster Linie die »schlechtesten Eigenschaften« zutage förderte. Obwohl der Industrialismus einerseits gewaltige »neue Energien« freisetzte, unterwarf er gleichzeitig die Welt einem »unheilvollen neuen System von Beziehungen«. Und hierzu schrieb er:

So gab er dem Stolz und der Gier des Menschen, dem Sadismus und dem Masochismus, dem Machtrausch und dem Rausch der Selbsterniedrigung starke Waffen und steigerte dadurch das Schuldgefühl der Menschen. So schuf er Organisationsprobleme, denen der Mensch nicht gewachsen ist und die ihn zu verschlingen drohen, und vervielfältigte dadurch die Ängste der Menschen. So nahm er schließlich den alten Religionen die Lebenskraft, ohne etwas Neues zu schaffen, das den Stolz und das Machtstreben hätte in Schach halten können; und erhöhte dadurch beides, Schuldgefühl und Angst. ${ }^{684}$

Vor dem Hintergrund seiner Ausführungen konstatierte er, dass was der Mensch in der damaligen Zeit an »Organisatorischem leisten« musste, über seine "sittlichen und gefühlsmäßigen Kräfte« hinausging. Für ihn war diese Tatsache die eigentliche Ursache »unserer seelischen Störungen«. Dieses Grunddilemma bot sich ihm in der Mitte des 20. Jahrhunderts vor allem in Gestalt des Konfliktes zwischen den Vereinigten Staaten und der Sowjetunion an. Indes: Für Schlesinger jr. stand auch fest, dass beide Nationen für das angesprochene Grunddilemma keine Lösung gefunden hätten, und zwar deshalb, weil sie nämlich kein »Mittel gegen die Verlockungen der Macht und die Korruption der Organisation« und die "menschlichen Schwächen« hatten. Nach seinen ausführlichen Reflexionen über die fundamentalen politischen Unterschiede zwischen dem Kapitalismus und Kommunismus (als "Kinder der industriellen Revolution«) US-amerikanischer und sowjetischer Provenienz stand für ihn fest, dass diese Unterschiede schlussendlich die Unterschiede zwischen einer "freien Gesellschaft» und einem »totalitären Regime« waren. ${ }^{685}$

In Anbetracht seiner Ausführungen über den grundsätzlichen ideologischen Konflikt zwischen den Vereinigten Staaten und der Sowjetunion und dem daraus resultierenden zeitgenössischen politischen, moralischen und militärischen Machtkonflikt sowie über die Illusion des 20 . Jahrhunderts, demzufolge nämlich der >Fortschritt< etwas »Unvermeidliches« sei, und der in diesem Zusammenhang vertretenen Ansicht, dass man in einem "Zeitalter des Übergangs « und mithin in einem `Zeitalter der Unsicherheit leben würde, ${ }^{686}$ unternahm Schlesinger jr. den Versuch, die bestehende existenzielle Krise zwischen den beiden unterschiedlichen politischen Systemen historisch zu erklären. Auf dieser Interpretationsgrundlage erfolgte dann - der hier interessierende - facettenreiche Vergleich zwischen dem Nationalsozialismus und dem Sowjetkommunismus.

684 Ebd., S. 342.

685 Siehe hierzu im Einzelnen mit ausdrücklichen Ausführungen zur »Konzeption einer freien Gesellschaft« und den »Merkmale[n] der Freiheiten« unter Berufung auf den englischen Premierminister Winston Churchill (ebd., S. 343-345).

686 Siehe hierzu im Einzelnen Arthur M. Schlesinger jr., Politik im Zeitalter der Angst, in: Der Monat 2 (1950), H. 16, S. 344 f. 
Auf der Grundlage seiner einleitenden Ausführungen über die Entstehungsbedingungen der (modernen) Industriegesellschaft und den hiermit verbundenen Zerstörungen der traditionellen (mittelalterlichen) Gesellschaften sowie den daraus resultierenden ausdrücklichen Kosten für das einzelne Individuum, die seiner Ansicht insbesondere in dem Verlust der »alten schützenden Sicherheiten « zu sehen waren ohne dass die moderne industrielle Wirtschaft, die auf »Unpersönlichkeit, Auswechselbarkeit und Tempo « beruhte, "neue Sicherheiten" schuf - sowie einer radikalen Kritik an den Kategorien >Angst des dänischen Philosophen Sören Kierkegaard und >Freiheit des zum damaligen Zeitpunkt einflussreichen Existenzialismus des französischen Philosophen Jean-Paul Sartre, meinte Schlesinger jr., dass die »meisten Menschen « aus Angst vor der Freiheit fliehen würden. Ebendiese »Flucht vor der Freiheit« (Erich Fromm) sah er als den »charakteristischen Grundzug unseres Zeitalters« an, da »der Mensch« gewohnt sei, »Glied eines Ganzen zu sein, aber er ist es nicht mehr: Die naturhaft gegebene Gesellschaft ist durch die vertragsmäßig gegründete Gesellschaft ersetzt worden, und das beklemmende Entweder-oder zwischen Halten und Brechen von Verträgen erzeugt Qual und Erschöpfung «. ${ }^{687}$

Die bisherigen komplexen Ausführungen dienten Schlesinger quasi als Vorspiel, um sich im Anschluss daran primär mit dem Phänomen des Totalitarismus im Allgemeinen und den totalitären Herrschaftssystemen des deutschen Nationalsozialismus und des sowjetischen Kommunismus im Besonderen auseinanderzusetzen. Im Kontext seiner Beschreibung und Analyse der totalitären Staaten zog er ausdrücklich den Vergleich. ${ }^{688}$

Er vertrat folgende grundsätzliche Ansichten: ${ }^{689}$

1. Je höher sich die Organisation über »dem Menschen auftürmt«, umso mehr und mehr würde dieser in »Verlorenheit, Ohnmacht und Furcht« leben.

2. Dass »der Mensch« im sogenannten Monopol- oder Staatskapitalismus seine Macht erweitert hatte und gleichzeitig »die Freiheit auf dem Gebiet der Wirtschaft« abnahm, sodass er den »Schlägen und Stößen ausweichen« möchte, die auf seine »schwache Individualität« einschlugen.

3. Dass die Analyse des Sozialpsychologen Erich Fromm durchaus zutreffen würde, wonach nämlich die "psychologischen Stigmata der Flucht vor der Freiheit« in dem "Streben nach Unterwerfung und nach Herrschaft« besteht sowie darin, dass »das Ich sich in Masochismus oder Sadismus« verliert.

Daraus folgte für ihn, dass der totalitäre Staat als das spezifische »Korrelat dieser Furcht vor der Freiheit« entstand und eine »Erfindung des 20. Jahrhunderts« sei. Der qualitative Unterschied bestehe zu den bis dahin bekannten Herrschaftsregimen, wie

687 Ebd., S. $345 \mathrm{f}$.

688 Im Folgenden wird die jeweils von Schlesinger jr. benutzte (Forschungs-)Literatur aus wissenschaftlichen Gründen in den Fußnoten aufgeführt.

689 Wie bereits zu Anfang zum Ausdruck gebracht wurde, ist es auch an dieser Stelle von Bedeutung, die dem ausdrücklichen Vergleich des deutschen Nationalsozialismus und des sowjetischen Kommunismus vorangestellten Ausführungen in der gebotenen Kürze voranzustellen, weil nur auf dieser inhaltlichen Grundlage die Gegenüberstellung der beiden totalitären Staaten von Schlesinger jr. verständlich wird. 
der Diktatur, dass diese sicherlich »blutig und tyrannisch« waren, aber die »Gesellschaftsstruktur größtenteils unangetastet« blieb. Das totalitäre Prinzip dagegen, so seine Meinung,

atomisiert die gesellschaftliche Struktur, indem es alle selbständigen Cruppen und auseinanderstrebenden Bindungen zu einer einzigen amorphen Masse zermahlt. Die Machtwirkung des totalitären Staates ist unbegrenzt. Diese Tatsache ist an sich schon eine Quelle seiner tiefgehenden psychologischen Werbekraft. Auf wirtschaftlicher Ebene sucht er auf die Zusammenhanglosigkeit und offensichtliche Unkontrollierbarkeit der industriellen Cesellschaft die Antwort zu geben. Auf der politischen und psychologischen Ebene wirbt er mit der Hoffnung, daß die nagenden Ängste zur Ruhe kommen werden; er bietet Institutionen, die den sadistischen und masochistischen Trieben ein Ventil öffnen. Als System gesellschaftlicher Organisation gibt er vor, dem Leben Sinn und Zweck zu verleihen. An Stelle der Einsamkeit und Wurzellosigkeit des Menschen in der freien Gesellschaft verspricht er die Sicherheit und Kameradschaft einer Kreuzfahrergemeinschaft, die von einem tiefen und anfeuernden Clauben getrieben wird.

Und weiter:

Der Mensch im Zeichen der Freiheit ist, nach Marschall Schukows vielsagender Wendung, »eine undisziplinierte, unausgerichtete Cegebenheit«; im Zeichen des Totalitarismus wird, wie Konstantin Simonows glücklicher Ausdruck lautet, jede Person »eine Partikel des Sowjetsystems «. »Sozialist sein heißt«, wie Goebbels es ausdrückte, »das Ich dem Du zu unterwerfen; Sozialismus bedeutet, das Individuum der Allgemeinheit zu opfern. ${ }^{690}$

Für ihn waren es diese »entwaffnenden Gründe«, worauf die »Werbekraft des totalitären Prinzips« beruhte, und er vertrat hierzu ausdrücklich den Standpunkt, dass »Ideologie und Logik« keineswegs die zentrale Rolle spielen würden. In diesem $\mathrm{Zu}$ sammenhang versuchte er ausschließlich mit Reflexionen zur kommunistischen Parteidisziplin sowie einem persönlichen Zitat aus einer Veröffentlichung vom ehemaligen Mitglied der KPF, André Malraux, einen Beleg für seine These zu finden. So hieß es bei Schlesinger jr.: " Früher waren unsere Leute diszipliniert, weil sie Kommunisten waren‘, bemerkte ein Held Malraux'. `Jetzt werden zahllose Leute Kommunisten, weil die Partei sich für Disziplin einsetzt. « ${ }^{691}$

Und vor dem Hintergrund von geschichtsphilosophischen Reflexionen im Allgemeinen - mit ausdrücklichem Blick auf das »Tausendjährige Reich« und auf die »Proletarische Revolution « - und der eigenartigen Anziehungskraft des Inhalts des kommunistischen »Glaubensbekenntnisses « im Besonderen meinte Schlesinger jr., dass der >Angstmensch der »charakteristische Bürger der freien Gesellschaft im 20. Jahrhundert« sei. Dass das totalitäre Prinzip letzten Endes triumphierte, war dem »Menschen ohne Angst« zu verdanken: Dem »totalitären Menschen«. Hierzu führte er aus:

690 Arthur M. Schlesinger jr., Politik im Zeitalter der Angst, in: Der Monat 2 (1950), H. 16, S. 346.

691 Zit. n. ebd., S. $346 f$. 
Der Totalitarismus unternimmt es, die tragischen Erkenntnisse zu liquidieren, die dem Menschen ein Gefühl für seine Beschränkung gegeben haben. Dafür hat er einen neuen Menschen gezüchtet, rücksichtslos, bestimmt, extravertiert, erhaben über Zweifel und Demut, fähig zu selbstherrlicher Sicherheit und in den höheren Rängen der Partei auch wirklich »unfehlbar«. Der »totalitäre Mensch« ist Koestlers Kommissar -»der Menschentyp, der die Verbindung zum Unterbewußten völlig gelöst hat«. ${ }^{692} \mathrm{Er}$ ist der Held André Malraux', der Mensch, der Massenwillen und geschichtliche Bestimmung verkörpert und damit im Gegensatz zu einem Individualismus steht, der auf der Pflege persönlicher Unterschiede beruht.

Der totalitäre Mensch verleugnet, was seine eigenen Nerven und sein privates Cewissen ihm sagen, bis beides vor der Autorität der Partei und der Ceschichte verkümmert ist. Er ist der Mensch, der von der absoluten Unfehlbarkeit der Partei, ihres Willens und Urteils überzeugt ist, der Agent, der keine bösen Ahnungen und keine Skrupel kennt, der Aktivist, der sein Leben ohne Zögern der Geschichte opfert. Wir kennen sie gut, die Cesichter dieser neuen Menschen, aus der Gestapo oder dem M.V.D., aus dem Politbüro oder der Versammlung der Vereinten Nationen: es sind schmallippige, kaltäugige, fühllose und verschlossene Menschen, wie aus rohem Holz geschnitzt, ohne Humor, ohne Ursprünglichkeit, ohne Nerven. ${ }^{693}$

Nach weiteren Ausführungen insbesondere zum totalitären Menschen - als Gegentypus zum Menschen der freien Gesellschaft - und seiner Bereitschaft, der (totalitären) Partei angesichts seines Glaubens, sie hätte die Geheimnisse der Geschichte und der Natur soweit gemeistert, dass ihr die einzelnen Subjekte bedingungslos zu folgen hätten, meinte Schlesinger jr., dass dies zur Ausprägung einer rücksichtslosen Mentalität führte. Die rücksichtslose Mentalität ging für ihn soweit, dass der Parteisoldat wusste, »wen er schonen und wen er töten soll«. Hier unternahm er anhand Koestlers Buch Sonnenfinsternis den Versuch, zu zeigen, dass aus der Perspektive eines gläubigen Kommunisten Stalin tatsächlich als die Inkarnation des Parteiführers der KPdSU und als das Staatsoberhaupt der Sowjetunion erscheinen konnte. Und zwar aus zwei Gründen: zum einen, weil Stalin möglicherweise tatsächlich den Geschichtsablaufs kannte, und zum anderen, weil er demzufolge vielleicht tatsächlich der Vollstrecker des Geschichtsprozesses war. Der »Anziehungskraft des Totalitären« lag für Schlesinger jr. die »Furcht vor Isolierung« und die »Flucht vor der Angst« zugrunde, und zwar umso mehr, wenn infolge einer wirtschaftlichen und moralischen Hoffnungslosigkeit "Furcht und Angst in Wahnsinn, in ein rabsolutes, schwarzes Vakuum « umschlugen. ${ }^{694}$

Auf den letzten knapp vier Seiten des ersten Teils seines Beitrages setzte er sich dann ausdrücklich in vergleichender Perspektive mit dem Faschismus, dem Nationalsozialismus und dem Kommunismus im Allgemeinen sowie mit dem deutschen und dem sowjetischen Totalitarismus im Besonderen auseinander. Die totalitären Regime des 20. Jahrhunderts verstanden sich in seinen Augen als genuin antidemokratische Bewegungen und traten auf den »Plan«, um sämtliche Konzeptionen »wirtschaftlicher oder politischer Wahlfreiheit radikal herauszufordern«. Für Schlesinger jr. existier-

692 An dieser Stelle berief sich der Autor auf das Buch von Koestler Der Yogi und der Kommissar, allerdings ohne Angaben zum Erscheinungsort und -jahr.

693 Arthur M. Schlesinger jr., Politik im Zeitalter der Angst, in: Der Monat 2 (1950), H. 16, S. 347

694 Ebd., S. 348. 
ten zwischen Kommunismus und Faschismus zwar wichtige Unterschiede, die seiner Meinung nach bei der Auseinandersetzung mit den Regimen und für das historische Verstehen durchaus von zentraler Bedeutung waren. Indes waren für ihn von einem bestimmten Zeitpunkt an die »Ähnlichkeiten unendlich viel stärker und bezeichnender«. Denn:

Die Ähnlichkeiten ergeben sich natürlich aus der Tatsache, daß beide Glaubensrichtungen als Antwort auf dieselben Enttäuschungen entstanden sind; sie tragen den Stempel derselben Mängel und Mißerfolge der freien Gesellschaft. Beide haben den »Angstmenschen« ersetzt durch den »totalitären Menschen«. Beide nützen die Revolutionsmystik aus, indem sie sich auf den tief im Volke wurzelnden Widerwillen gegen legitim gewordene Ungleichheiten gründen. In beiden Systemen hat die Unterdrückung der politischen Opposition und der Geistesfreiheit der herrschenden Partei absolute Macht verliehen, und in beiden Systemen sorgt eine alles durchdringende und erbarmungslose Geheimpolizei dafür, daß die Macht absolute Macht bleibt. In beiden Systemen spielen sich die charakteristischen Machtkämpfe innerhalb der herrschenden Schicht ab; in beiden Systemen leben die Massen in einer tief, trance-ähnlichen politischen Apathie. ${ }^{695}$

Nach seinen Ausführungen über die Ähnlichkeiten zwischen den Systemen des Kommunismus und Faschismus brachte Schlesinger jr. die »Wesensverwandtschaft« sämtlicher Vertreter des »totalitären Prinzips « zur Sprache. Seiner Ansicht nach bestand nämlich ebendiese Wesensverwandtschaft darin, dass sich die Exponenten des totalitären Prinzips in der unmittelbar zurückliegenden Geschichte gegen die »Gemäßigten zusammenstanden" - wie zum Beispiel während der Weimarer Republik im Kontext des Berliner Verkehrsstreiks vor »Hitlers Machtergreifung«. Zudem entsprach es Schlesinger jr. zufolge einfach einer historischen Tatsache, dass es einen »Übergang« von der extremen Linken zur extremen Rechten und zurück gab, der ebenfalls für die angesprochene Wesensverwandtschaft sprach. Kein Geringerer als Hitler sagte einmal, dass es

mehr Verbindendes als Trennendes zwischen uns und dem Bolschewismus [gibt] [...]. Vor allem die echte revolutionäre Cesinnung [...]. Ich habe diesem Umstand immer Rechnung getragen und Anweisung gegeben, daß man die ehemaligen Kommunisten sofort in die Partei aufnimmt. Aus den kleinbürgerlichen Sozialdemokraten und Cewerkschaftsbonzen wird nie ein Nationalsozialist, aus Kommunisten immer. ${ }^{696}$

Die Kommunisten bekundeten Schlesinger jr. zufolge nach dem Tod Hitlers ihr komplettes Einverständnis mit diesem Ausspruch, indem sie einen »besonderen Werbefeldzug unternahmen, um die kleinen Nazis in die kommunistisch beherrschte Sozialistische Einheitspartei der Sowjetischen Zone Deutschlands zu bringen«. Zudem sah er sowohl in der Verachtung des »Willensmenschen[en] « gegenüber dem »Mann des Wortes« als auch im antibürgerlichen Ressentiment des sogenannten Aktivisten

695 Ebd., S. 349.

696 Ebd., S. 349. Als Quelle für das Zitat diente dem Autor das Buch von Hermann Rauschning Gespräche mit Hitler; indes ohne Angaben zum Erscheinungsjahr und -ort sowie ohne Seitenzahl. 
eine weitere Verwandtschaft bei den Exponenten des totalitären Prinzips; zudem existierte auf einer "niedrigeren Ebene« ein »verzehrender Neid«, eine radikale $A b$ lehnung der »bestehende[n] Ordnung« sowie eine »Neigung zur Gewalttat« und eine »Lust am Gangstertum«. Gleichwohl erfuhren auch die »idealistischen Triebkräfte« im deutschen und sowjetischen Totalitarismus durchaus vergleichbare Schicksale. Seiner Ansicht nach hatten nämlich der Nationalsozialismus und der Sowjetkommunismus

ursprünglich ein gut Teil »echten revolutionären Gefühls«, aber beide landeten, wie es in allen Revolutionen der Fall ist, im Thermidor: Die Spannung zwischen den Bedürfnissen der Revolution und den Bedürfnissen des neuen Regimes wurde unerträglich. Die Organisation vernichtet schließlich die Revolution, und wahrscheinlich vernichtet sie damit auch einige der führenden Revolutionäre. ${ }^{697}$

Im Anschluss an diese Ausführungen thematisierte Schlesinger jr. die entscheidenden Aspekte, die beim Nationalsozialismus zum »Putsch vom Juni 1934« und beim Sowjetkommunismus zum Phänomen der Parteisäuberung führten. Vor dem Hintergrund seiner These, wonach die »Organisation« letzten Endes die Revolution »vernichtet«, insistierte er auf den »revolutionären Flügel« um Gregor Strasser im Nationalsozialismus, in dem sich eine rantikapitalistische Sehnsucht vermengte. Indes: Nach seiner Meinung siegte im innerparteilichen Machtkampf schlussendlich der »konservativere Hitler« über den Strasser-Flügel und deren Programm, das eine "sozialistische Revolution und eine Verbindung mit den Sowjets vorsah«. Die sozialrevolutionären Motive wurden in der einzigen nationalsozialistischen Organisation mit einer »starken proletarischen Gefolgschaft«, der SA, gebündelt, die durch ihren Führer, Hauptmann Ernst Röhm, nach der staatlichen Machteroberung den in ihren Augen »legitimen « Anteil und in diesem Kontext die >Zweite Revolution forderte. Angesichts der sich herauskristallisierenden Gefahr für die »konservativen Kräfte« zwang die »Armee«, so Schlesinger jr., Hitler zum Handeln, sodass dieser die Ermordung von Röhm und Strasser ins Werk setzte und zudem Goebbels, Koch und einige andere »revolutionäre Weggenossen zur Unterwerfung « zwang. Und in diesem Zusammenhang stellte er fest: »Ein paar Tage später sang ihnen Hitler die Elegie, die allen Opfern aller Thermidore gesungen wird - den >Revolutionären, welche die Revolution um der Revolution willen betreiben und sie als einen Dauerzustand betrachten möchten ...« ${ }^{698}$

In diesem Zusammenhang traf Schlesinger jr., nach seinem Hinweis, dass der »Apostel« der dauernden Revolution selbstverständlich Trotzki war, die Feststellung, dass die sowjetischen »Säuberungsaktionen«, die für ihn in den »berühmten« Moskauer Prozessen ihren »Höhepunkt« fanden, zusammen mit »Hitlers Säuberung« im Juni 1934 als »Schulfall« dafür gelten könne, wie »die Organisation die Revolution zerstört, wie die Bürokratie sich gegen die Radikalen wendet «. ${ }^{699}$

Im Anschluss an seine totalitarismustheoretisch fundierten Ausführungen und seinen ausdrücklichen Vergleichen zwischen dem Nationalsozialismus (bzw. Faschis-

697 Arthur M. Schlesinger jr., Politik im Zeitalter der Angst, in: Der Monat 2 (1950), H. 16, S. 349 f.

698 Ebd., S. 350. Als Quelle für das Zitat diente dem Autor das Buch von Hans Bernd Gisevius Bis zum bitteren Ende; indes ohne Angaben zum Erscheinungsjahr und -ort sowie ohne Seitenzahl.

699 Arthur M. Schlesinger jr., Politik im Zeitalter der Angst, in: Der Monat 2 (1950), H. 16, S. 350. 
mus) und dem Sowjetkommunismus stellte Schlesinger jr. sodann fest, dass ebenjene Herrschaftssysteme mithin aus einer »echt revolutionären Unzufriedenheit« mit der existierenden Gesellschaft entsprangen. Gleichwohl waren seiner Meinung nach die »revolutionären Ansätze« zum Scheitern verurteilt und wurden von der »neuen herrschenden Klasse« bekämpft, genauer »niedergetreten«, der sie »zur Macht« verhalfen. Allerdings gab es für ihn »bedeutsame Unterschiede«. Während der Faschismus in seinen Augen ein eindeutiger »Ausdruck des Nihilismus « war, wahrte, so der Autor, der Kommunismus den Anschein, als stünde er »inmitten eines Systems greifbarer Werte«. Will heißen: Was der Faschismus an »Beweisgründen« aufzuweisen hatte, gehörte für ihn ins »Reich des Somnambulismus«; die Argumentation stand im Zeichen von »Mythos, Psychose und Blut«. Der »Marxismus« wiederum hatte Schlesinger jr. zufolge dem Kommunismus ein »beachtliches geistiges Erbe mitgegeben, das mit Wertbegriffen aus dem Optimismus, Rationalismus und der historischen Einzelforschung des 20. Jahrhunderts angereichert « war. ${ }^{700}$

Vor dem Hintergrund eines ausführlichen Exkurses zur geistesgeschichtlichen Entwicklung des Marxismus zu einer genuinen Ideologie, die sich in der politischen Herrschaftspraxis der Bolschewiki auch und vor allem nach der Russischen Revolution primär durch den »totalitären Glauben« auszeichnete, der für Schlesinger jr. bereits frühzeitig auch als sozialpsychologischer Kitt der lange Zeit im Geheimen operierenden »festgefügte[n], disziplinierte[n] Elite« fungierte, stellte er fest, dass sich bei dieser Parteielite im Laufe der Zeit mehr und mehr eine »Verschwörermanie« ausbreitete, die zur "Zweiten Natur des Kommunismus« geworden sei. ${ }^{701}$

Nach seinen vergleichenden Reflexionen und Urteilen zum Faschismus und dem Kommunismus, die sich allerdings in erster Linie auf den Marxismus und auf die Entwicklung der Bolschewiki zur führenden Partei des sowjetischen Staates bezogen, konstatierte er im vorletzten Absatz seines Beitrages, dass der Totalitarismus in Deutschland für ihn ein »Musterbeispiel für die Flucht vor der Freiheit« war. Dementsprechend konnten sich im Nationalsozialismus seiner Meinung nach die in »sadistische und masochistische Richtung zielenden Triebe « am »wildesten ausleben«. Und in diesem Zusammenhang stellte er explizit fest:

Der Totalitarismus in Russland dagegen ist etwas Umfassenderes und Verwickelteres. Insofern als der Stalinismus nur eine moderne Erscheinungsform der kollektivistischen Empfindungen ist, die ununterbrochen in der russischen Geschichte gewirkt haben, hat er gewissermaßen etwas Legitimes und Cesetzmäßiges. Es fehlen ihm nämlich die psychotischen und gewalttätigen Züge, die der Totalitarismus in einem Lande aufweist, das die Freiheit gekannt hat. ${ }^{702}$

Gleichwohl gab es für ihn noch weitere zentrale Unterschiede zwischen den beiden »Spielarten des totalitären Prinzips«, denn:

700 Ebd

701 Siehe im Einzelnen ebd., S. 350 f. Als Quelle diente dem Autor die Schrift W. I. Lenin, Was tun?, indes ohne Angaben zum Erscheinungsort und -jahr sowie ohne Seitenangabe.

702 Arthur M. Schlesinger jr., Politik im Zeitalter der Angst, in: Der Monat 2 (1950), H. 16, S. 351. 
Der Faschismus ließ die Wirtschaftsstruktur des Privateigentums bestehen. Der Staat übernahm zwar das Recht zu fundamentalen wirtschaftlichen Entscheidungen; und führende politische Gestalten wie Göring schnitten sich riesige Lehnsgüter aus dem Wirtschaftskörper heraus. Aber es gab keine systematische Enteignung der besitzenden Klasse und daher keine Liquidierung der bis dahin herrschenden Bevölkerungsteile. Als Bewegung des kleinen Mittelstand empfand der Nationalsozialismus gegenüber den großen Besitzhäufungen eher Neid als Mißbilligung; im Cegensatz zum Kommunismus als einer Bewegung der Arbeiterklasse hatte der Nationalsozialismus auch kein tieferes Verlangen nach Abschaffung des privaten Ausbeutertums. ${ }^{703}$

Dies musste dem Nationalsozialismus, schrieb Schlesinger jr. zu Beginn des nächsten und letzten Absatzes seines Beitrages weiter, »auf kurze Sicht stark und auflange Sicht verwundbar machen«. Denn, so führte er aus:

Hitler verbündete sich mit den willfährigen Vertretern des Croßkapitals, des Landadels, der Beamtenschaft und der Armee und gewann auf diese Weise unmittelbaren Zugang zu einem unschätzbaren Reservoir von Fachkräften, während Lenin nur allzu oft improvisieren mußte, weil seine Generäle nicht kommandieren, seine Ingenieure nicht bauen und seine Diplomaten [...] nicht verhandeln konnten. Aber nachdem die Sowjetunion sich so eine Ceneration lang durchgebissen hatte, verfügte sie über Ceneräle, Ingenieure und Diplomaten, denen sie mehr oder weniger trauen konnte, deren Verrat schlimmstenfalls der eines Einzelnen, nicht der einer ganzen Klasse war.

Und Schlesinger jr. schrieb bezogen auf das nationalsozialistische Herrschaftssystem mit dem Fokus auf das Thema »Verrat« wie folgt weiter:

Hitler dagegen fand sich, sobald das Schicksal sich gegen ihn wandte, von Männern umgeben, die ihn jederzeit verraten konnten, und die Männer aus der Armee, dem Auswärtigen Amt, der Beamtenschaft benutzten dabei die Mittel und den Rückhalt, die ihre Klasse ihnen bot. In seinen letzten Tagen pflegte Hitler deshalb Vertrauten gegenüber gedankenvoll zu sagen, daß Lenin und Stalin recht daran getan hätten, die Oberschicht in Russland auszutilgen, und daß er einen Fehler begangen habe, indem er nicht ebenso handelte. Vielleicht wurde ihm bei einem solchen Rückblick klar, daß er 1934 eine falsche Wahl getroffen hatte.

Vor dem Hintergrund seines historischen Urteils, wonach in diesem Kontext Hitler für seinen »Irrtum « mit dem sogenannten Putschversuch vom 20. Juli bezahlen musste, und weiteren Ausführungen zum deutschkonservativen Widerstand gegen den »Führer« kam Schlesinger jr. auf die »Gruppe radikaler Aktivisten« zu sprechen, die für ihn vom Grafen von Stauffenberg angeführt wurde. Nach seinem Dafürhalten lebte in dieser Gruppe die »alte Gregor-Strasser-Sehnsucht« nach einem »wahrhaft revolutionären Nationalsozialismus« auf dem »Boden eines Bündnisses mit der Sowjetunion« auf "seltsame Weise« wieder auf. Nach dem gescheiterten »Putschversuch« tat Hitler in den Augen von Schlesinger jr. alles in seiner Macht Stehende, um seinen »Fehler von 
1934 wiedergutzumachen«, und schrieb zum Schluss des ersten Teils der beiden Auszüge aus seiner Studie The Vital Center:

So machte die Liquidierung der alten herrschenden Eliten die Übergangsschwierigkeiten für die Russen gewiß größer, ihre jetzige Stellung jedoch viel sicherer. Das nationalsozialistische Deutschland verkörperte im besten Fall einen unvollkommenen Totalitarismus. Allzu viel Elemente des früheren Deutschlands lebten in verhältnismäßig guter Beschaffenheit weiter darin fort, als daß Staat und Gesellschaft wirklich zur Deckung gebracht werden konnten. Die Sowjetunion hingegen scheint eine Einheit von Staat und Gesellschaft zustande gebracht zu haben, die ihrer Anlage nach vollständig ist und deren Nahtstellen gegen Wind und Wetter abgedichtet sind. Auf großer Fahrt wird es sich wahrscheinlich erweisen, daß das Schiff der Sowjetunion erheblich seetüchtiger ist als das zusammengeflickte Fahrzeug der Nationalsozialisten. ${ }^{704}$

In dem zweiten Teil seiner Veröffentlichung Politik im Zeitalter der Angst (H. 19) setzte sich Schlesinger jr. ausschließlich mit dem Totalitarismus sowjetischer Couleur auseinander, wobei seine Ausführungen explizit und implizit in totalitarismustheoretischer Perspektive geschrieben wurden und den Systemvergleich zwischen dem Nationalsozialismus und dem Sowjetkommunismus intendierte. Auf den ersten sechs Seiten beschrieb und analysierte Schlesinger jr. ausdrücklich die gesellschaftliche und politische Entwicklung des sowjetischen Staates unmittelbar in den Jahren nach der Oktoberrevolution von 1917 unter der Führung von Lenin, die für ihn auf der ideologischen Grundlage des Marxismus erfolgte. Hierbei legte er den Fokus seiner Ausführungen auf drei zentrale Gesichtspunkte:

1. Auf die Genesis der KPdSU als Staatspartei und auf ihre komplexe Rolle im Zusammenhang mit dem Phänomen des Terrors, der bei der blutigen Unterdrückung des Protestes der »revolutionären Matrosen« von Kronstadt im März 1921 durch die unter dem Kommando von Trotzki stehenden sowjetischen Truppen für Schlesinger jr. einen ersten negativen Höhepunkt erreichte. ${ }^{705}$

2. Unter der Überschrift »Bürokratischer Kollektivismus« auf die totale Unterdrückung der sowjetischen Bevölkerung, genauer der »amorphen Massen« durch eine neue Herrscherklasse, die über die staatlichen Produktionsmittel verfügte, die ihre Herrschaft primär durch die totalitäre Geheimpolizei sicherte. ${ }^{706}$

3. Unter der Überschrift »Terror und Widerstand« auf den militärischen und politischen Widerstand des »russischen Volk(es)« gegen ein totalitäres Regime (Leninismus/Stalinismus) und hier speziell auf die sogenannte Befreiungsarmee des General Wlassow. ${ }^{707}$

Im Zusammenhang seiner Ausführungen zur grundsätzlichen Bedeutung des Widerstands und der oppositionellen Bewegung für das sowjetische Herrschaftssystem lie-

704 Ebd.; Hervorh. des Verf.

705 Siehe im Einzelnen Arthur M. Schlesinger jr., Politik im Zeitalter der Angst, in: Der Monat 2 (1950), H. 19, S. 68-70.

706 Ebd., S. $70 f$.

707 Ebd., S. 71. 
ferte Schlesinger jr. eine Definition für den Totalitarismus, die sich sowohl auf den »Rechts-«als auch auf den »Linkstotalitarismus« bezog. Hierzu führte er aus:

Totalitarismus bedeutet, daß die gesamte soziale Energie, jede innere Bindung, jede Gemüts- und Claubenskraft in einem einzigen Brennpunkt gesammelt wird; diese Konzentration macht es notwendig, den ganzen Organismus der Gesellschaft ständig in hoher Spannung zu halten. Totalitäre Staaten haben im allgemeinen diese Spannung aufrechterhalten, indem sie äußere oder innere Gefahren aufbauschten: einen aggressiven Staat von außen oder eine teuflische Verschwörung im Innern. Verschwinden die wirklichen äußeren Bedrohungen, so wird das Regime mehr und mehr dazu gezwungen, den notwendigen Grad von Spannung mit Hilfe inneren Terrors aufrechtzuerhalten, statt die Zügel seiner Herrschaft lockern zu können. ${ }^{708}$

Nachdem Schlesinger jr. in diesem Kontext auch auf die unterschiedlichen Voraussetzungen für den leninistischen und den stalinistischen Terror insistierte, kam er auf die Bedeutung der Konzentrationslager und auf die Rolle des Terrors zu sprechen und beleuchtete aus seiner Sicht das Wesen der totalitären Herrschaftsform. Hierzu führte er aus:

Hannah Arendt hat gezeigt, daß sich die Konzentrationslager sowohl in Russland wie in Deutschland nicht zu der Zeit vervielfältigten, als die Opposition gegen das Regime am wirksamsten war, sondern gerade nach ihrem Erlöschen. Je länger das totalitäre Regime besteht und je sicherer es vor inneren und äußeren Feinden ist, desto notwendiger wird offenbar der Terror, desto wilder werden die Ketzerverfolgungen, desto ungestümer setzt sich die Forderung nach einer totalen Claubenseinheit durch.

Im Allgemeinen also wird der Totalitarismus im Laufe der Zeit eher stärker als schwächer werden, doch darf man an diesem Punkt nicht zu dogmatisch sein. Sowohl das Deutschland Hitlers wie Sowjetrussland standen in ihren späteren Entwicklungsphasen zweifellos unter dem Einfluß echter oder eingebildeter Furcht vor Angriffen von außen; ebenso könnte eine spürbare Hebung des Lebensstandards sehr wohl die Notwendigkeit des Zwanges und der Spannung einschränken und damit auch den Terror. Aber eine totalitäre Herrscherklasse ist gewissermaßen das Opfer der Dynamik ihres eigenen Systems. Sobald das Politbüro einmal eine Entscheidung getroffen hat, muß es an seiner eigenen Unfehlbarkeit festhalten. [...] Der Hauptfeind ist die Angst, sie darf im eigenen Lager nicht geduldet werden. So wird der totalitäre Mensch dazu getrieben, ständig seine Überzeugung zu erhärten, daß er absolut im Recht ist, und zwar nicht nur alle zu vernichten, die ihn unmittelbar herausfordern, sondern auch diejenigen, die durch ihr Tun Strömungen in der Cesellschaft entstehen lassen, die von dem allesverschlingenden Zentralstrudel hinwegführen. ${ }^{709}$

Auf der Basis dieser grundsätzlichen Reflexionen zum Wesen des totalitären Herrschaftssystems setzte er sich im Anschluss daran ausschließlich mit der zeitgenössischen Entwicklung des sowjetischen Staates auseinander. Unter der Überschrift »Der Verlust der kulturellen Freiheit« beleuchtete er differenziert den »jüngste[n] so- 
wjetische[n] Feldzug gegen die kulturelle Freiheit« in den Jahren nach dem Ende des Zweiten Weltkrieges, der sich unter anderem durch den radikalen Angriff gegen den »verruchte[n] >Kosmopolitismus« « auszeichnete und der insbesondere mit den »Parteiintellektuellen« wie Konstantin Simonow oder Alexander Fadejew sowie den international bekannten »fellow-travellers « um Eliot, Dos Passos, Sartre oder auch Malraux geführt wurde. ${ }^{710}$

Und im letzten Abschnitt seines Beitrages kam Schlesinger jr. unter der Überschrift "Die Konzentrationslager als Sinnbild« im Zusammenhang seiner Aussage, dass das Konzentrationslager, »wie es Hannah Arendt glänzend dargelegt hat «, zum »Sinnbild« des Totalitarismus im 20. Jahrhundert avancierte, auf den Konnex zwischen totalitärer Herrschaft, willkürlichen Verhaftungen von Menschen, der ökonomischen Bedeutung der Zwangsarbeit in den Konzentrationslagern und Terror zu sprechen. ${ }^{71}$

Nachdem im August 1949 (H.11) Jaesrich in einem Rezensionsaufsatz auf das kurz zuvor in England und den Vereinigten Staaten erschienene Buch 1984 von Orwell ausführlich einging, ${ }^{712}$ wurde kurz darauf der utopische Roman in fünf Teilen mit jeweils einführenden Worten der Redaktion vollständig abgedruckt. ${ }^{713}$ Nicht zuletzt angesichts der persönlichen Erfahrungen des Anhängers der politischen antifaschistischen Linken und Kämpfers in den republikanischen Reihen im Spanischen Bürgerkrieg sowie frühen Gegners des Nationalsozialismus und des Stalinismus ${ }^{714}$ entwarf George Orwell in seiner Antiutopie das Schreckbild einer totalitären Gesellschaft in der Zukunft. »Der Ausgangspunkt«, so die Zeitschriftenredaktion in den einführenden Worten des ersten Teils,

seiner unerbittlichen Phantasie und seines blutigen Spottes ist seine Heimat - ein England, das auf der Bahn der Verstaatlichung und Bürokratisierung bedeutend weiter fortgeschritten ist, als es der englische Sozialismus von heute erwarten läßt, ein England, das durch die Preisgabe der persönlichen Freiheit, deren Hort es heute ist, seine eigenen Schwächen mit den Greueln von Faschismus und Stalinismus vereinigt. Orwell erreicht damit, seine Leser vor jeder erdenklichen Form des Totalitarismus abzuschrecken, obwohl er die Entwicklung zu dem teuflischen Staat des Jahres 1984 fast als etwas Unabwendbares darstellt. ${ }^{715}$

Während sich der enge Freund Orwells und Herausgeber der englischen sozialistischen Wochenschrift Tribune, T. R. Fyvel, in seinem Beitrag Zum Tode George Orwells (H. 19) mit dessen Reflexionen im Buch 1984 hinsichtlich des Missbrauchs der Sprache im Rahmen des »Studiums des kommunistischen Jargons« im Allgemeinen und im

710 Ebd., S. 72-74.

711 Siehe ebd., S. 75. Auf die konkreten Ausführungen von Schlesinger jr. gehe ich im Kap. IV.3.3 ein.

712 Hellmut Jaesrich, Fünfunddreißig Jahre weiter ... Zu George Orwells neuem Roman »Neunzehnhundertvierundachtzig«, in: Der Monat 1 (1949), H. 11, S. 115-119 (Rezension).

713 Siehe die Veröffentlichung der fünf Teile von: George Orwell, »1984«. Ein utopischer Roman, in: Der Monat 2 (1949), H. 14, S. 115-137 (Teil I), H. 15, S. 239-277 (Teil II), 2 (1950), H. 16, S. 357-391 (Teil III); 2 (1950), H. 17, S. 485-521 (Teil IV) sowie abschließend H. 18, S. 570-602 (Teil V).

714 Siehe hierzu im Einzelnen Kap. II.4 und die Ausführungen zu George Orwell in Kap. II.4.4.

715 Redaktionelles Vorwort in: Der Monat 2 (1949), H. 14, S. 115. 
Nationalsozialismus im Speziellen auseinandersetzte, ${ }^{716}$ nahm Jaesrich in seinem bereits genannten Rezensionsaufsatz Fünfunddreißig Jahre weiter ... Zu George Orwells neuem Roman »Neunzehnhundertvierundachtzig« im letzten Abschnitt einen ausdrücklich totalitarismustheoretischen Blick ein und schrieb unter anderem:

In seinem Ozeanien hat Orwell mit der echten Leidenschaft des Satirikers die künftigen Schrecknisse aller uns heute bekannten Gesellschaftsformen vereinigt. Das Grundthema, vor allem die Antithese zwischen dem großen Bruder Stalin und Coldstein-Trotzki, ist genau wie in »Animal Farm« den sowjetischen Verhältnissen entnommen, viele wesentliche Züge sind dem Nationalsozialismus abgeschaut. ${ }^{717}$

Ebenfalls im zweiten Jahrgang des Erscheinens des Monat gingen Borkenau und der auch aus Deutschland stammende Renegat Salter im Rahmen ihrer Rezensionen zweier Bücher zur Geschichte der Sowjetunion in vergleichender Perspektive auf das Phänomen der totalitären Herrschaftssysteme ein. Während Salter kurz auf das für ihn interessante Phänomen totalitärer Staaten und ihrer Ideologen hinwies, dass sie nämlich eine »offene und geheime Scheu vor der Psychologie haben, vor allem vor der Tiefenpsychologie ${ }^{718}$ versuchte Borkenau - in erster Linie mit Blick auf den Stalinismus - die überragende Bedeutung des Terrors sowohl für das "Stalin-Regime«als auch für das »Hitler-Regime« zu erklären bzw. zu interpretieren. Im Kontext seiner kritischen Anmerkungen anlässlich einer im Grunde genommen »uneingeschränkte[n] Verherrlichung von Stalins historischer Leistung « von Isaac Deutscher in seiner 1949 in England erschienenen Stalinbiografie ${ }^{719}$ schrieb Borkenau - vor dem Hintergrund eines Vergleichs von Hitler und Stalin, einer Analogie zwischen dem jakobinischen Terror der Französischen Revolution und dem "roten Terror « im russischen Bürgerkrieg von 1918 bis 1920 und des stalinistischen Terrors sowie des Versuchs Isaac Deutschers, den neuartigen Charakter des Terrors als "permanente Institution« unter Stalin gewissermaßen zu verwischen - dass durch ebendiese »Verschiebung der Perspektive« zweifelsohne die »allzu offenkundigen Parallelen zwischen Stalin und Hitler, zwischen dem Kommunismus stalinscher Prägung und dem Nationalsozialismus« verschwanden. Und weiter hieß es in diesem Zusammenhang nach ausdrücklichen Bemerkungen zu den Anfängen des stalinistischen Terrors Anfang der 1930er-Jahre nach der Einführung des ersten Fünfjahresplanes in der Sowjetunion:

Dann mußte die Terrorwelle mit dem Ende der akutesten Phase der Umwälzung, also etwa 1933, beendet sein, und das war auch von vielen Beobachtern erwartet worden. In Wahrheit fielen jedoch die scheußlichsten Phasen des Terrors in die Zeit nach diesen Vorgängen. Der Terror hat eben im heutigen sowjetischen System mit sozialen Umwäl-

716 T. R. Fyvel, Zum Tode George Orwells, in: Der Monat 2 (1950), H. 19, S. 84-87, hier S. 85 f.

717 Hellmut Jaesrich, Fünfunddreißig Jahre weiter ... Zu George Orwells neuem Roman »Neunzehnhundertvierundachtzig«, in: Der Monat 1 (1948), H. 11, S. 118.

718 Ernest ). Salter, Der permanente Terror, in: Der Monat 2 (1950), H. 16, S. 435-439, hier S. 438 (Sammelrezension).

719 Franz Borkenau, Stalin im Schafspelz. Zu einer neuen Biographie von Isaac Deutscher, in: Der Monat 2 (1949), H. 14, S. 204. 
zungen überhaupt nichts mehr zu tun, er ist, ganz wie im Nationalsozialismus und aus ganz denselben Gründen, eine dauernde Institution, er ist das Regime selbst. ${ }^{720}$

Und weiter hieß es bei Borkenau an anderer Stelle seiner Rezension der Stalinbiografie im Anschluss an weitere Ausführungen zur Bedeutung des permanenten Terrors als übergreifendes Gesetz des stalinschen Regimes und einem expliziten Vergleich mit dem deutschen Terrorregime: „Das innere Gesetz des stalinistischen, nicht weniger als das des nationalsozialistischen Terrors treibt (wenn auch in der Sowjetunion langsamer als in Deutschland) zum Konflikt mit der Welt und damit zu einer Totalkatastrophe nicht nur für das terroristische Regime, sondern auch für das von ihm geführte Land. $\ll^{721}$

Nach den Ausführungen von Borkenau zur zentralen Rolle des Terrors für das stalinistische und nationalsozialistische Herrschaftssystem im Rahmen seiner Rezension der Stalinbiografie von Deutscher kam Hans von Rimscha in seinem Leserbrief (H. 18) zum Borkenau-Beitrag auch auf die Gemeinsamkeiten des »braunen« mit dem »roten« Terror zu sprechen. Am Ende seines Artikels Zweierlei Terror schrieb von Rimscha - vor dem Hintergrund seiner grundsätzlichen analytischen Reflexionen zu den historisch-politischen Gemeinsamkeiten des leninistischen und stalinistischen Terrors und seinen konkreten Ausführungen zum genuin politischen Terror Stalins, der sich gegen »jeden Gegner« richtete und deshalb auch so lange in Gang bleiben musste, als es »wirkliche oder vermeintliche« Gegner gab:

So wurde er logischerweise zu einer permanenten Institution, das heißt zu einem integrierenden Bestandteil des Herrschaftssystems. Ihm fielen denn auch, wie ein jeder weiß, in erster Linie nicht Klassenfeinde, sondern politisch feindliche oder auch nur oppositionelle Klassengenossen, sehr viele Arbeiter und noch mehr Bauern zum Opfer. Seinem Typus nach unterscheidet sich dieser Terror durch nichts vom Terror Hitlers und Himmlers. $^{722}$

In der nächsten Ausgabe des Monat, im April 1950 (H.19), wurde in zwei Leserbriefen in vergleichender Perspektive auf den totalitären Staat deutscher und sowjetischer Couleur eingegangen. Während Jorg Lampe in seinem Beitrag Persönlichkeit und Masse auf einer abstrakten Ebene das erklärungsbedürftige Verhältnis des totalitären Führers und der Bevölkerung, genauer gesagt die Begeisterung und die Zustimmung die ebendiesem Führer seitens der Individuen der diktatorischen Regime zuteilwurde, beleuchtete (ohne sich allerdings konkret auf den Nationalsozialismus und den Sowjetkommunismus zu beziehen), ${ }^{723}$ vertrat Ivan L. Rudnytsky in seinem Artikel Antisowjetisch oder anti-russisch - der sich in erster Linie mit der Bevölkerungspolitik im »Vielvölkerstaat « der kommunistischen Machthaber auseinandersetzte -, angesichts seines Hinweises, dass nicht alle Bewohner der Sowjetunion als >Russen zu klassifi-

720 Ebd., S. 205.

721 Ebd., S. 208.

722 Hans v[on] Rimscha, Zweierlei Terror, in: Der Monat 2 (1950), H. 18, S. 671 f., hier S. 672. Der Beitrag bezog sich, wie angemerkt wurde, auf die Rezension von Borkenau (H. 14) zu der Stalin-Biografie von Isaac Deutscher und somit zuallererst auf den sowjetischen Kommunismus; siehe hierzu speziell das Kapitel IV. 2.4, in dem der Leserbrief von Hans von Rimscha fast komplett zitiert wird.

723 Siehe Jorg Lampe, Persönlichkeit und Masse, in: Der Monat 2 (1950), H. 19, S. 108-110. 
zieren und zu beurteilen seien, die Ansicht, dass in den westlichen Staaten allzu häufig die Tatsache übersehen wurde, dass die UdSSR »kein Nationalstaat« sei, und fügte hinzu, dass ebendies »ein wichtiger, immer wieder vergessener Unterschied zwischen dem sowjetischen und dem früheren nationalsozialistischen Totalitarismus! « sei. ${ }^{724}$

Am Ende des zweiten Jahrgangs des Monat, also in Heft 24 (September 1950), begann die Zeitschrift mit dem Vorabdruck von insgesamt drei Kapiteln aus der erst im darauffolgenden Jahr in New York erschienenen Studie The Origins of Totalitarianism von Arendt. Nach der Veröffentlichung Der imperialistische Charakter. Eine psychologisch-soziologische Studi ${ }^{725}$ folgten im dritten Jahrgang die Reflexionen zur Totalitären Propaganda (H. 33) ${ }^{726}$ und im vierten Jahrgang das bedeutende Kapitel Die Geheimpoli$z e i\left(\right.$ H. 46) ${ }^{727} \mathrm{Da}$ bereits im Verlauf der vorliegenden Untersuchung sowohl auf zentrale Aussagen der beiden letztgenannten Kapitel eingegangen ${ }^{728}$ als auch der Inhalt des »Imperialismus-Kapitels« aus der Studie Elemente und Ursprünge totaler Herrschaft (mit-)beleuchtet wurde, ${ }^{729}$ muss hier der Hinweis genügen, dass sie mit geringen $\mathrm{Ab}$ weichungen vom Monat komplett abgedruckt wurden, ${ }^{730}$ indes ohne den größten Teil

724 Ivan L. Rudnytsky, Anti-sowjetisch oder anti-russisch, in: Der Monat 2 (1950), H. 19, S. 104-107, hier S. 104.

725 Hannah Arendt, Der imperialistische Charakter. Eine psychologisch-soziologische Studie, in: Der Monat 2 (1950), H. 24, S. 509-522.

726 Dies., Totalitäre Propaganda. Ein Kapitel aus »Die Ursprünge des Totalitarismus«, in: Der Monat 3 (1951), H. 33, S. 241-258.

727 Dies., Die Geheimpolizei. Ihre Rolle im totalitären Herrschaftsapparat, in: Der Monat 4 (1952), H. 46, S. 370-388.

728 Siehe die entsprechenden Ausführungen im Einleitungskapitel und Kap. IV.3.1.

729 Bei dem Beitrag Der imperialistische Charakter. Eine psychologisch-soziologische Studie (H. 24) handelte es sich um das Kapitel 7/III »Die imperialistische Legende und der imperialistische Charakter« aus dem zweiten Teil über den »Imperialismus« der späteren deutschen Ausgabe Elemente und Ursprünge totaler Herrschaft (1955), in dem sich Arendt vor dem Hintergrund der Entstehung der sogenannten britischen imperialistischen (Gründungs-)Legende mit der imperialistischen Macht- und Expansionspolitik, der kolonialen rassistischen Verwaltungsbürokratie und -praxis Englands vor allem in Ägypten unter Lord Cromer und in Südafrika unter Cecil Rhodes sowie den damit verbundenen politischen Implikationen für die englische Nation in den Jahren von 1884 bis 1914 auseinandersetzte. Vgl. hierzu Kap. Il.1 der vorliegenden Untersuchung, die entsprechenden Ausführungen im Kontext der grundsätzlichen Thematisierung der Cenese des aus dem Kolonialismus resultierenden kontinentalen und transatlantischen europäischen Imperialismus in der Zeitspanne von 1884 bis 1914 sowie der Arendt zufolge hiermit verbundenen sukzessiven Untergrabung der Stabilität der europäischen Nationalstaaten.

730 Zu den geringen Abweichungen zählten die beiden folgenden Aspekte: Einerseits fehlte in dem Beitrag Der imperialistische Charakter. Eine psychologisch-soziologische Studie (H. 24) der Hinweis auf die letztlich nicht ernsthaft gemeinte (»utopische«) Idee eines Bürokraten des britischen Imperialismus für einen `Verwaltungsmassenmord Mal verwirklicht wurde; andererseits hieß es am Ende des Beitrages Totalitäre Propaganda (H. 33) auf S. 258, »dass vermutlich neunzig Prozent des deutschen Volkes irgendwann einmal überzeugte Anhänger oder Sympathisierende der Nazis gewesen waren «. In dem gleichnamigen Kapitel der später dt. Ausgabe Elemente und Ursprünge totaler Herrschaft (1955) war »nur« noch von vermutlich 80 Prozent die Rede. 
des Fußnotenapparates ${ }^{731}$ und ohne dass in diesem Zusammenhang von der Redaktion - bis auf einige wenige Informationen zur Herausgabe der amerikanischen und zur geplanten deutschen Ausgabe sowie einem Hinweis zum »Sonderdruck ${ }^{732}$ - irgendwelche einführenden Worte erfolgten. ${ }^{733}$

Gleichwohl rückte die Totalitarismusstudie von Arendt in einem anderen Beitrag des Monat ins Blickfeld. In dem Rezensionsaufsatz anlässlich der Veröffentlichung der Festschrift für Karl Jaspers ging der deutsche Philosoph Hans Kudszus auf den hier abgedruckten Aufsatz Ideologie und Terror ein und schrieb vor dem Hintergrund seiner grundsätzlichen Beurteilung des Beitrages von Arendt, dass es sich um eine "glänzende Analyse« handeln würde:

Wenn Hannah Arendt den Terror als das eigentliche Wesen der totalitären Herrschaft bestimmt, so besagt dies noch so gut wie nichts, solange die Begriffe nicht mit den Bedeutungsgehalten gesättigt sind, die sich die Verfasserin in völlig eigenständigen Gedankenentwicklungen erarbeitet hat. Und wenn sie die Grunderfahrung menschlichen Zusammenseins, die in totalitärer Herrschaft politisch realisiert wird, in der Erfahrung der Verlassenheit findet, in der jeder von jedem, von der Welt und auch vom eigenen Selbst verlassen und auf nichts mehr Verlaß ist, so mag das manchen nicht sonderlich neu sein; es ist aber neu durch die Verbindung, in die es Hannah Arendt etwa zum zwangsläufig-zwingenden Deduzieren der immer extremistischen und radikalen Ideologien und zum Terror bringt. An solche Dinge denken wir, wenn wir meinen, daß die konzentrierte, in bestechende Begrifflichkeit gefaßte Arbeit zu den ganz seltenen Meisterleistungen soziologisch-politischer Cegenwartsanalyse gehört. ${ }^{734}$

731 Die Veröffentlichung Der imperialistische Charakter erfolgte mit dem fast kompletten Fußnotenapparat, der späteren deutschen Ausgabe Elemente und Ursprünge totaler Herrschaft. Die Veröffentlichung Totalitäre Propaganda erfolgte mit einigen wenigen und Die Geheimpolizei ohne Fußnoten.

732 Der Monat veröffentlichte nämlich die beiden in der Zeitschrift erschienenen Kapitel Totalitäre Propaganda und Die Geheimpolizei. Ihre Rolle im totalitären Herrschaftsapparat aus der Studie von Arendt vorab auch in Broschürenform als »Sonderdruck«. Einer redaktionellen Annonce nach, die in der Augustausgabe 1952 (4, H. 47, S. 555) abgedruckt wurde, erschien der Sonderdruck vom Monat unter dem Titel Der Totalitarismus. Gedanken über Geheimpolizei und Propaganda.

733 Abgesehen davon zählte es zu den bemerkenswerten Umständen, dass entgegen der gängigen Zeitschriftenpraxis, zu bedeutenden zeitgenössischen politischen, kulturellen oder auch wissenschaftlichen Themen unter den Autoren eine inhaltliche Diskussion in Gang zu bringen, bei der Vorabveröffentlichung der drei Kapitel von Arendt darauf verzichtet wurde, obwohl die Redaktion - in der Rubrik »Die Autoren des Monats«, in: Der Monat 3 (1951), H. 33, S. 333, sowie im Rahmen der Veröffentlichung des Kapitels Die Ceheimpolizei in den ausschließlich bibliografischen Hinweisen zur amerikanischen und englischen Buchausgabe und zu den beiden zuvor erschienenen Kapiteln auf die zentrale Bedeutung der Totalitarismusstudie hinwies. Ausschließlich in einem Leserbrief wurde auf den Beitrag Die Geheimpolizei eingegangen, indes primär mit dem Blick aufden Stalinismus; siehe Walter Birkhahn, Zur Praxis des Polizeistaates, in: Der Monat 4 (1952), H. 47, S. 545.

734 Hans Kudszus, Von der Gefährdung des Menschen. Zur Festschrift für Karl Jaspers, in: Der Monat 5 (1953), H. 56, S. 188-191, hier S. 190 (Rezension). Vgl. in diesem Zusammenhang auch die ausdrücklichen Ausführungen und Reflexionen zu dem Kapitel »Ideologie und Terror«von Carl Linfert, Erschlaffte Liberalität, in: Der Monat 5 (1953), H. 58, S. 423-429, hier S. 425 f.; auf S. 425 wurde Arendts Beitrag Ideologie und Terror als eine »großartige Abhandlung« apostrophiert. 
Nachdem im Verlauf des dritten Jahrganges die Auseinandersetzung mit dem Nationalsozialismus und dem Kommunismus insbesondere in den Veröffentlichungen des englischen Philosophen und politischen Theoretikers Isaiah Berlin erfolgte, der in seinen beiden Aufsätzen Der Einbruch des Irrationalen (H.28) und Der Weg zum Konformismus (H.29) - jeweils mit dem Untertitel Politische Ideen im 19. und 20. Jahrhundert - explizit und implizit die politisch-geistesgeschichtlichen Voraussetzungen für das Phänomen der (prä-)totalitären Bewegungen des 20 . Jahrhunderts untersuchte, ${ }^{735}$ rückte der Vergleich des deutschen und sowjetischen Gewaltregimes in einer Veröffentlichung Laskys (H. 36) ins Blickfeld. In seinem bereits herangezogenen Beitrag Die Moskauer Geständnisse. Gedanken über Ketzerei und Opposition im totalen Staat ${ }^{736}$ setzte er sich bekanntlich primär mit dem stalinistischen Terror in den Jahren 1936 bis 1938 auseinander. Gleichwohl verglich Lasky hierbei auch den Nationalsozialismus mit dem Stalinismus. Vor dem Hintergrund seines Versuches einer historisch-politischen Erklärung der großen Tschistka und einer Interpretation der "Geständnisse« zahlreicher verhafteter Gefangener des Stalinismus, die für ihn nicht zuletzt durch brutale Foltermethoden des NKWD erpresst wurden, verglich Lasky mit einem expliziten und impliziten Verweis auf Arendts Argumentationslogik den stalinistischen mit dem nationalsozialistischen Terror. Für ihn unterschied sich der Terror unter Stalin im Vergleich zur »improvisierten Mordlust Hitlers« besonders dadurch, dass der NS-Terror von der Voraussetzung ausging, dass es »objektive Gegner« gäbe und »seien sie auch (wie etwa im Falle der Juden oder der Zigeuner) noch so sunerwünscht«. Und in diesem Kontext führte er bei seinem Vergleich des nationalsozialistischen mit dem stalinistischen Herrschaftssystem Folgendes aus:

Ein vergleichendes Studium der Cewaltanwendung stellt viele Fallen und bietet viele Schwierigkeiten. Beobachter der braun- und der rotgefärbten Sozialordnung, des nationalsozialistischen und des sowjetischen Systems, haben sich allzu häufig von der trügerischen Oberfläche der Dinge täuschen lassen. Das Ergebnis sind zahllose Illustrationen beinahe jeder Form des logischen und methodologischen Irrtums. Besonders beliebte Irrtümer unter den Betrachtern der gegenwärtigen politischen Verhältnisse sind die falsche Cleichsetzung und die falsche Cegenüberstellung.

Für eine pseudoeinfache Auffassung sind Kommunismus und Nazismus strukturell und geistig das gleiche Phänomen. Dieser übereilige Monismus, häufig nur ein geistreicher Versuch, möglichst alles unter den Hut eines einzigen Prinzips oder einer einzigen Kategorie zu bringen, geht meiner Ansicht nach auf zwei Quellen zurück. Die erste ist die sentimentale Vorstellung,

735 Siehe laiah Berlin, Der Einbruch des Irrationalen. Politische Ideen im 19. und 20. Jahrhundert, in: Der Monat 3 (1951), H. 28, S. 339-348 (Teil I), sowie ders., Der Weg zum Konformismus. Politische Ideen im 19. und 20. Jahrhundert, in: Der Monat 3 (1951), H. 29, S. 461-469.

736 Melvin ]. Lasky, Die Moskauer Ceständnisse. Cedanken über Ketzerei und Opposition im totalen Staat, in: Der Monat 3 (1951), H. 36, S. 648-654 (Rezension); siehe die ausführliche inhaltliche Zusammenfassung des Rezensionsaufsatzes - der sich, wie gesehen, vor dem Hintergrund einer genuin totalitarismustheoretischen Perspektive primär mit dem stalinistischen Terror auseinandersetztein Kap. IV.2.4. 
daß alles sowohl moralisch wie propagandistisch sich vereinfacht, sobald man Hitler und Stalin als "ganz dasselbe«, als "gleich schlecht« betrachten kann. Die zweite besteht in dem chronischen Bedürfnis des Soziologen nach Gleichsetzung und Parallelen, weil Unterscheidungen die Dinge nur komplizierter machen und das wahre Wesen der Dinge nur zu trüben geeignet sind.

Der andere beliebte Irrtum beruht darauf, Nazi-Deutschland und Sowjetrussland als ein Gegensatzpaar aufzustellen, als zwei »grundlegend verschiedene« Formen der Regierung und der Ideologie. Die Wurzeln dieses Irrtums reichen zu den Überbleibseln einer liberalistisch-idealistischen Naivität zurück, die den Kommunismus immer als ein Kind der Aufklärung und des Rationalismus, den Faschismus als die düstere Hervorbringung des Nihilismus betrachtet hat.

Er schrieb abschließend:

Die Vertreter der Hitler=Stalin-Schule rufen in uns den unbestimmten Verdacht hervor, daß sie sich, falls die Bolschewisten sich auch nur eine Nuance weniger bösartig als die Nazis erweisen sollten, platterdings außerstande betrachten würden, den Kampf gegen den Kommunismus länger fortzusetzen. Die andere Auffassung, zu deren Anhängern z. B. Thomas Mann gehört, verkrampft sich verzweifelt in der Vorstellung des Cegensatzes: wenn diese Leute nicht länger an einem Unterschied zwischen den beiden Diktaturen glauben könnten, wären die Ärmsten ja gezwungen, zu einer konsequenten anti-totalitären Haltung überzugehen. ${ }^{737}$

Nach diesen substanziellen Ausführungen am Ende des dritten Jahrganges des Monat zum Nationalsozialismus und zum Stalinismus im Allgemeinen und den grundsätzlichen kritischen Reflexionen zu den sowohl wissenschaftlichen als auch politischen Problemen des genuinen Vergleichs der beiden totalitären Herrschaftssysteme im Besonderen folgte - neben einem totalitarismustheoretisch inspirierten Exkurs im Bereich der Architektur von Hermann Beenken ${ }^{738}$ - nur zwei Zeitschriftenausgaben

737 Ebd., S. 652 f. Auf die weiteren Ausführungen in seinem Beitrag zu den deutschen und sowjetischen Konzentrationslagern von Melvin ]. Lasky gehe ich im kommenden Kap. IV.3.3 ein.

738 Hermann Beenken, Vom Experiment zum Prunkstück. Dreißig Jahre sowjetische Architektur, in: Der Monat 4 (1951), H. 38, S. 183-185, schrieb auf S. 185 im Zusammenhang seiner primär auf die Funktion der Architektur im sowjetischen Kommunismus bezogenen Ausführungen u. a.: »Nicht die Form, sondern die Gesinnung ist wichtig. Die Architektur soll wieder als ein Mittel, Ideologien und Illusionen zu stützen und die Massen zu beherrschen, verstanden werden. Sie hat eine Kunst des schönen Scheines zu sein, jedoch nicht nur das. Sie errichtet nicht nur überall die Kulturfassade, sondern formt auch die Menschen als Masse und zwingt sie ins Kollektiv. Der Nationalsozialismus hatte das nur unzureichend vermocht. Seiner Parole >Blut und Boden< entsprechend, hatte er Siedlungen mit Einzelhäusern, Einzelgärten und damit die `kleinbürgerliche Idylle`des Individualismus begünstigt. Die Masse hatte er nur zu den großen nationalen Festen, etwa in Anlagen wie denen des Nürnberger Parteitags, fassen und formen können. Der Bolschewismus geht folgerichtiger vor. Er formt bereits das Wohnen der Masse und sichert sich die Kontrolle. Er löst die Menschen vom Erdboden und begrenzt von vornherein die Spielräume möglichen Eigennutzes. Der Einzelne hat sich stets nur als mehr oder minder begünstigter Teil der Masse zu fühlen, und auch wo er wohnt, nur als Gast, nicht viel anders als in den großen Sportstadien, den Theatern, Kinos und Kulturpalästen, die man überall baut. Er ist nichts aus sich selber, sondern daseinsfähig nur als Teilchen und Funktionär des alles übergreifenden Apparats.«(Hervorh. des Verf.) 
später ein weiterer. In Laskys Rezensionsaufsatz über Churchills Kriegserinnerungen, der im November 1951 (H.38) erschien, hieß es bei ihm mit Blick auf Ausführungen des englischen Premierministers im Winter 1940/41: „Er wusste, daß >Hitler und Stalin als Diktatoren vieles gemein hatten, daß ihre Regierungssysteme einander verwandt waren<, aber er gab nicht viel auf die Lebensdauer des von Molotow und Ribbentrop ausgearbeiteten $>$ Zehnjahres-Vertrages $<.{ }^{739}$

An anderer Stelle zitierte Lasky eine längere Passage aus den autobiografischen Erinnerungen von Churchill, die nach dem deutschen Überfall auf die Sowjetunion am 22. Juni 1941 enstanden. Vor dem Hintergrund des bevorstehenden Übereinkommens mit Stalin über ein gemeinsames Bündnis gegen »Hitler-Deutschland« verglich der überzeugte Antikommunist Churchill, der zum damaligen Zeitpunkt angesichts der deutschen Gefahr nur ein Ziel kannte, nämlich »Hitlers Vernichtung«, den Nationalsozialismus mit dem sowjetischen Kommunismus:

\begin{abstract}
"Das Naziregime unterscheidet sich in nichts von den schlimmsten Seiten des Kommunismus. Es ist abgesehen von seiner Gier und seinem Rassenwahn nur skrupellos und bar jedes ethischen Prinzips. Es übertrifft alle Formen menschlicher Verworfenheit durch Rationalisierung der Grausamkeit und raubtierhafte Aggressionslust. Niemand ist ein unversöhnlicherer Cegner des Kommunismus gewesen als ich selbst seit fünfundzwanzig Jahren. Ich nehme nicht ein einziges Wort zurück, das ich zu dem Thema gesagt habe. Doch alles verblasst vor dem Schauspiel, das sich jetzt abwickelt. Die Vergangenheit mit ihren Verbrechen, ihren Torheiten und Tragödien versinkt. Ich sehe die russischen Soldaten an der Schwelle ihres Vaterlandes wachen und sehe sie die Felder schützen, die ihre Vorväter seit undenklichen Zeiten beackert haben. [...] Und ich sehe die Nazikriegsmaschine über sie alle in scheußlicher Wildheit hereinbrechen [...]. Und ich sehe auch die stumpfen, gedrillten, willfährigen und brutalen Massen dieser hunnischen Soldateska wie ein Heuschreckenschwarm das Land überkriechen. [...]

Hinter all diesem Blendwerk, hinter all diesen Sturm sehe ich die kleine Gruppe verbrecherischer Männer, die diese Überfälle und diese Sturzflut von Schreckenstaten planen und organisieren...
\end{abstract}

Wir haben nur ein Ziel, eine einzige unwiderrufliche Aufgabe. Wir sind entschlossen Hitler und jede Spur des Naziregimes zu vertilgen. Davon wird uns nichts abbringen nichts. Wir werden uns nie auf ein Gespräch mit ihm einlassen, nie mit ihm oder einem aus seiner Bande verhandeln. Wir werden ihn bekämpfen zu Land, wir werden ihn bekämpfen zur See [...] Wer, Mensch oder Staat, gegen den Nazismus kämpft, wird unseren Beistand haben. Wer, Mensch oder Staat, mit Hitler marschiert, ist unser Feind .. Das ist unsere Proklamation. Daraus folgt, dass wir Russland und dem russischen Volk jede mögliche Hilfe gewähren, die wir gewähren können. « $^{740}$

Wiederum zwei Ausgaben später (H.40) setzte sich Hudson mit den beiden »Großtotalitarismen « auseinander. In seinem im Januar 1952 erschienenen Beitrag Die Toten von Katyn. $\mathrm{Zu}$ den neuesten polnischen Geschichtsquellen thematisierte er in seinem Re-

739 Melvin ]. Lasky, Churchill und Stalin. Ein Streifzug durch Winston Churchills Kriegserinnerungen, in: Der Monat 4 (1951), H. 38, S. 141-154 (Rezension), hier S. 142.

740 Ebd., S. $143 f$. 
zensionsaufsatz die zu diesem Zeitpunkt für die internationale Öffentlichkeit einer Aufklärung und näheren Erklärung harrenden genauen historischen Umstände des Massenmordes von Katyn. ${ }^{71}$ Trotz der veröffentlichten zeitgenössischen Untersuchungen zum »Fall Katyn« war zum damaligen Zeitpunkt nicht endgültig sicher, wer den Massenmord an Tausenden polnischen Offizieren nach dem Überfall der deutschen Wehrmacht auf Polen im September 1939 begangen hatte, weil letzten Endes nicht geklärt werden konnte, zu welchem genauen Zeitpunkt die Morde durchgeführt wurden. ${ }^{72}$ Gleichwohl sprach - wie gezeigt ${ }^{743}$ - für Hudson in Anbetracht der zeitgenössischen Indizien sehr viel für die Tatsache, dass der sowjetische Geheimdienst NKWD als Täter infrage kam, die 1939 im Zuge des Überfalls Polens durch deutsche Truppen neben den Massenmorden auch Tausende von polnischen Offizieren (sowie Generäle und Soldaten) gefangen nahmen und in sogenannte gesonderte sowjetische Konzentrationslager deportierten.

Die totalitarismustheoretische Komponente des »Falles Katyn« lag unter anderem darin, dass angesichts des Hitler-Stalin-Paktes und der nationalsozialistischen Bekanntgabe im April 1943 durch den Propagandaminister Goebbels, dass man im Wald von Katyn (unweit von Smolensk) ein »Massengrab« entdeckt habe, so Hudson in seinem Beitrag, sich fortan die deutsche und die sowjetische Regierung gegenseitig beschuldigten, verantwortlich für das Verbrechen an den "polnischen Untertanen « (Hudson) zu sein. Das heißt, in diesem Zusammenhang bezichtigten sich zwei totalitäre Herrschaftsregime sozusagen mit den gleichen Methoden, sprich: Propaganda und Lüge, gegenüber der internationalen Öffentlichkeit des Massenverbrechens. ${ }^{744}$

Im Mai des Jahres 1952 (H.44) veröffentlichte Der Monat unter der Überschrift "Totalitäre Demokratie« einen ins Deutsche übersetzten Auszug aus der soeben in London erschienenen Untersuchung The Origins of Totalitarian Democracy Talmons; ${ }^{745}$ hierbei handelte es sich um das Eingangs- sowie Schlusskapitel. Die ideengeschichtlich ausgerichtete Totalitarismusstudie des Professors für neuere Geschichte an der Hebräischen Universität in Jerusalem und früheren Absolventen der Londoner School of Economics, wo er mit einer Arbeit über The Doctrines of Poverty in the Middle Ages promovierte und wo nicht zuletzt Harold J. Laski zu seinen »Lehrern « zählte, ${ }^{746}$ avancierte bekanntlich zu einem Klassiker der Totalitarismustheorie. ${ }^{747}$

Da die herausragenden Aussagen bzw. Thesen der talmonschen Studie mithin bereits als bekannt vorausgesetzt werden können, sollen im Folgenden die ausführlichen einleitenden Worte der Redaktion des Monat zitiert werden. Hiermit soll ein Eindruck vermittelt werden, worin die redaktionelle Gruppe der Zeitschrift um Lasky die zentrale Bedeutung des Buches über die Ursprünge der »totalitären Demokratie«

741 G.f. Hudson, Die Toten von Katyn. Zu den neuesten polnischen Quellenschriften, in: Der Monat 4 (1952), H. 40, S. 403-407 (Sammelrezension).

742 Ebd., S. 407.

743 Siehe die entsprechenden Ausführungen in Kap. IV.2.8.

744 Zu dem Beitrag von G.f. Hudson vgl. auch den Leserbrief: Josef Mackiewicz, Nachtrag zu Katyn, in: Der Monat 4 (1952), H. 42, S. 667 f.

745 ][acob] L. Talmon, Totalitäre Demokratie, in: Der Monat 4 (1952), H. 44, S. 155-164.

746 Mitteilungen der Zeitschriftenredaktion in der Rubrik»Die Autoren des Monats«, in: Ebd., S. 219.

747 Siehe die entsprechenden Ausführungen zur Studie im Einleitungskapitel und in Kap. IV.3.1.1. 
sah. Hierzu hieß es mit ausdrücklichem Blick auf die sowjetische Besatzungszone in Ostdeutschland:

Ist nicht die Demokratie dort, wo es freie Wahlen, eine unbevormundete Presse und ungehinderte Meinungsfreiheit des Einzelnen gibt? Herrscht nicht jenseits der Markierung, im Bereiche einer von oben ernannten Volkskammer, eines SSD [sic!], einer sowjetisch gesteuerten Presse, genau das Cegenteil? Und doch ist der Anspruch auf Demokratie, auf die einzig wahre Demokratie, auf den weißen Schimmel »Volksdemokratie«, vielleicht kein völlig willkürlicher Akt der Prahlerei, sondern eher der letzte, freilich groteske Ausdruck eines tragischen Verhängnisses. Denn schließlich pocht eine der grimmigsten Diktaturen hier nicht allein deshalb auf Demokratie, auf »Volksherrschaft«, weil heute kein Regierungssystem mehr auf dieses Etikett verzichten darf, sondern weil der Begriff tatsächlich einmal ihren weltanschaulichen Ausgangspunkt gebildet hat. Aber wie »Fortschrittlichkeit« und »Humanität« ist die Parole in einem erkennbaren historischen Ablauf von einem erfüllten Wert zu einem hohlen Anspruch geworden. J. L. Talmons Aufsatz zeigt den Degenerationsprozeß auf, der an dem einen der beiden, ursprünglich aus gleicher Wurzel entsprungenen Zweige des modernen DemokratieBegriffes sich vollzogen hat, und sucht nachzuweisen, daß diese Entwicklung von dem Augenblick an vorgezeichnet war, da man sich die abstrakten Forderungen Rousseaus zu eigen machte. Eine Rettung sieht Talmon nur bei der anderen Form der Demokratie, die das Ceschick der Cemeinschaft einem geordneten, doch frei experimentierenden Kräftespiel anvertraut. ${ }^{748}$

Nachdem Borkenau in seiner Studie Vom Kreislaufder Eliten. Zum dreißigsten Todestage Vilfredo Paretos (19. August 1923) in Heft 59 in nuce auch auf die divergierenden Revolutionsmodelle und auf die unterschiedlichen Strategien der staatlichen Machteroberungen der Bolschewiki und der Nazis einging und in diesem Kontext insbesondere den »Großen Terror « Mitte der 1930er-Jahre unter Stalin thematisierte, ${ }^{749}$ erschien in derselben Ausgabe der Beitrag Über den Juni-Aufstand von Salter. Im Zusammenhang seiner differenzierten Auseinandersetzung mit den Ereignissen des 16./17. Juni 1953 in Ostberlin und in der sowjetischen Besatzungszone verglich der Autor das Totalitarismusmodell nationalsozialistischer und stalinistischer Couleur. In Anbetracht seiner einführenden Worte, derzufolge die »faschistische Barbarei« die deutsche Arbeiterbewegung demoralisiert und die Prinzipien der Rebellion in die »Geheimschränke der totalitären Bibliotheken verbannt« hatte, ${ }^{750}$ hieß es im Hinblick auf die beiden totalitären Staaten, dass die Grundsätze der »sozialistischen Solidarität« auch in den Jahren nach dem Ende des Zweiten Weltkrieges nicht wiederbelebt wurden, weil, so Salter, »die zweite große totalitäre Diktatur der modernen Geschichte« in der »einen Hälfte Deutschlands als militärische Besatzungsmacht in Erscheinung«trat. »Sie«, so der Autor weiter,

748 Redaktionelles Vorwort zu ][acob] L. Talmon, Totalitäre Demokratie, in: Der Monat 4 (1952), H. 44, 155. Zu dem Beitrag von Talmon siehe auch den Leserbrief: Jay Blumler, Empirismus oder unfanatischer Idealismus, in: Der Monat 4 (1952), H. 47, S. 548-550.

749 Siehe Franz Borkenau, Vom Kreislauf der Eliten. Zum dreißigsten Todestage Vilfredo Paretos (19. August 1923), in: Der Monat 5 (1953), H. 59, S. 493-502, hier S. 501.

750 Ernest ]. Salter, Über den Juni-Aufstand, in: Der Monat 5 (1953), H. 59, S. 545-548, hier S. 545. 
liquidierte die faschistische Diktatur der Hitler und Coebbels mit Hilfe einer neuen Diktatur. Die Gestapo wurde vom NKWD abgelöst, über den Konzentrationslagern des Dritten Reiches gingen die Hakenkreuzfahnen nieder und es stiegen die roten Fahnen auf: Die Draperie wechselte, aber weiter bestand die schrankenlose Herrschaft einer kleinen Gruppe über Millionen von Arbeitern und Bürgern, deren Interessen, in einer zwölfjährigen Periode des Staatsterrors vergewaltigt, unberücksichtigt blieben. Die Solidarität der Arbeiter konnte nicht neu erstehen, da die Ceheimpolizei jede soziale Gruppe zersetzte. Was der Perfektion der Gestapo noch ermangelte, wurde durch den SSD [sic!] ergänzt, der die Erfahrungen aus dem Sowjet- und dem Hitlerreich kombinieren konnte. ${ }^{751}$

Und an anderer Stelle seines Beitrages verglich Salter den »Hitler-Staat « direkt mit dem Stalinismus. Vor dem Hintergrund seiner Reflexionen zu den revolutionären Bedingungen unter einer »totalen Polizeiherrschaft« und der seiner Meinung nach in diesem Kontext unmöglichen »organisierte[n] Aufstandsbewegung « - denn für ihn mussten "außerordentliche Ereignisse « auftreten, damit im Laufe der Aktionen selbst der »Polizeiapparat paralysiert und ohnmächtig« gemacht werden könne - sowie mit Blick auf die Ereignisse in Ostdeutschland und der weit verbreiteten Vorstellung, dass ein totalitäres Regime eine »Massenaktion« unmöglich machen würde, hieß es bei ihm: »Alle Theoretiker des Antistalinismus ließen sich bisher von dieser Abstraktion leiten, weil sie den Erfahrungen in der Sowjetunion, aber auch den Bedingungen des deutschen SS-Staates durchaus entsprochen hatte. ${ }^{752}$

Nach Salters vergleichender Analyse der totalitären Herrschaftssysteme aus Deutschland und der Sowjetunion und seines grundsätzlichen politischen Urteils, wonach die sowjetisch beherrschte SED-Diktatur im Grunde genommen mit dem NSRegime in ihrem Wesen identisch waren, weil beide Herrschaftsregime einen totalen Polizeistaat darstellten, dessen jeweilige Bevölkerung von einer kleinen »verbrecherischen Clique beherrscht wurde, die ihre schrankenlose Macht mit den genuinen Herrschaftsinstrumenten der Geheimpolizei sowie der Konzentrationslager sicherten, war es in der nächsten Ausgabe des Monat Aron, der sich dem Vergleich des Nationalsozialismus und des Stalinismus sozusagen widmete.

In seinem Artikel Glaube ohne Illusionen, der im Septemberheft des Jahres 1953 (H.60) erschien, vertrat Aron im Rahmen seiner grundsätzlichen Ausführungen speziell zur Rolle der Gewalt und der industriellen Technik im Jahrhundert der »modernen Barbarei« einerseits - unter anderem mit einem Exkurs zu den sowjetischen und nationalsozialistischen Konzentrationslagern ${ }^{753}$ - und andererseits angesichts der existenziellen Systemauseinandersetzung der westlichen Welt mit dem Kommunis-

751 Ebd., S. 546.

752 Ebd., S. 547.

Vgl. auch in diesem Zusammenhang die beiden - durchaus in vergleichender Perspektive geschriebenen - ausführlichen Beiträge zur politischen und gesellschaftlichen Genese des »]uni-Aufstandes«: ohne Namen, Der Aufstand im Juni. Ein dokumentarischer Bericht (Teil I), in: Der Monat 5 (1953), H. 60, S. 595624, sowie (Teil II), in: Der Monat 5 (1953), H. 61, S. 45-66 (mit jeweils längeren einführenden Worten der Zeitschriftenredaktion); indes: Der Vergleich des NS-Regimes mit dem sowjetischen Besatzungsregime in Ostdeutschland beschränkte sich hierbei darauf, gemeinsame Wesenszüge der beiden Herrschaftsregime ausschließlich festzustellen und beide Regime quasi als Terrorsysteme zu charakterisieren.

753 Siehe hierzu die Ausführungen in Kap. IV.3.3. 
mus sowjetischer Provenienz die These, dass die zeitgenössischen totalitären Systeme »nichts Neues« wären. »Neu« waren für Aron »nur ihre Methoden« ${ }^{754}$

Im Verlauf der nächsten vier Jahrgänge des Monat kam es zu keiner grundsätzlichen vergleichenden Auseinandersetzung mit den totalitären Herrschaftsregimen des Nationalsozialismus und des Sowjetkommunismus sowie zu keiner substanziellen Gegenüberstellung des Terrorphänomens. Wie in dem vorherigen Kapitel zur »Analyse des Sowjetkommunismus« auch und vor allem gezeigt werden konnte, rückte nach dem Tod Stalins die Beschreibung und Analyse des nachstalinistischen Herrschaftssystems in den Brennpunkt des Interesses der internationalen Zeitschrift. Infolgedessen waren die Experten für das facettenreiche Phänomen des Totalitarismus wie Borkenau, Kohn oder auch Lasky in erster Linie mit den gesellschaftlichen und politischen Veränderungen, sprich dem Wandlungsprozess im sowjetkommunistischen System und den osteuropäischen Satellitenstaaten, schlechthin beschäftigt. Ebendieser Wandlungsprozess harrte für die politisch und wissenschaftlich interessierten Zeitgenossen und besonders für die international renommierten Kommunismusexperten des Monat (Richard Löwenthal, Arthur Koestler, David Dallin, Boris Nikolajewski, Wanda Bronska-Pampuch, Ruth Fischer, Ernest Salter, Boris Meissner, George Fischer, Bertram D. Wolfe, Edward Crankshaw, Hugh Seton-Watson oder Ernst Halperin) einer differenzierten Erklärung und Interpretation, sodass dieser Personenkreis auch dieses Medium für ihre Veröffentlichungen nutzte.

Mit Blick auf dieses Kapitel der vorliegenden Arbeit bildete der im Juniheft des Jahres 1957 (H. 105) erschienene Beitrag Die Hölle aufErden. Despotie im zwanzigsten Jahrhundert von Löwenthal sozusagen den Abschluss. ${ }^{755} \mathrm{Da}$ es sich um die letzte Veröffentlichung im Monat handelte, in der substanzielle Reflexionen zu diesem Themenkomplex angestellt wurden, zumal aus einer explizit vergleichenden beschreibenden und analytischen Perspektive, sollen im Folgenden die löwenthalschen Ausführungen knapp referiert und im Hinblick auf die entscheidenden Aussagen zitiert werden.

Eingedenk der zentralen Verbrechen aus der ersten Hälfte des 20. Jahrhunderts, nämlich den »Gaskammern von Auschwitz« und den »Protokollen der Moskauer Prozesse«, so Löwenthal, war er im Gegensatz zu vielen (namentlich nicht genannten) Zeithistorikern der Ansicht, dass, »was wir mangels eines kürzeren Namens Totalitarismus nennen", zweifelsohne etwas Neues und Singuläres darstellte - im Vergleich zu den bis dahin bekannten traditionellen Herrschaftsregimen wie beispielsweise der (asiatischen) Despotie oder der Tyrannei (wie im alten Griechenland). Für Löwenthal stand nämlich in diesem Zusammenhang fest:

In Wirklichkeit aber weist der moderne Totalitarismus Züge auf, die allen Sklavenstaaten, Theokratien und revolutionären Tyranneien der Vergangenheiten fehlen. Er enthält wohl Elemente aus allen dreien, fügt sie aber in einen neuen Zusammenhang. Er ist nicht statisch, sondern gebietet über eine industrielle Volkswirtschaft mit schnell sich wandelnden Produktionsmethoden; seine Religion ist weltlich; die Tyrannis setzt die

754 Raymond Aron, Glaube ohne Illusion, in: Der Monat 5 (1953), H. 60, S. 563-571, hier S. 570; hierbei handelte es sich um das letzte Kapitel aus seinem in Deutschland erschienenen Buch Derpermanente Krieg (Frankfurt o. J.).

755 Richard Löwenthal, Die Hölle auf Erden. Despotie im zwanzigsten Jahrhundert, in: Der Monat 9 (1957), H. 105, S. 3-8. 
revolutionären Umwälzungen innerhalb der Gesellschaft fort. Einerseits ist totalitäre Diktatur gerade im Zeitalter der Massendemokratien entstanden; sie will ihre Untertanen nicht zu politischer Untätigkeit, sondern zu aktiver Unterstützung ihrer nie endenden Kampagnen zwingen. Andererseits geht sie darauf aus, alle Bezirke einer sehr vielfältigen und differenzierten Gesellschaftsordnung zu beherrschen, jeden Rest unabhängiger Kräfte, jeden Keim einer ideologischen Abweichung zu vernichten. ${ }^{756}$

Vor dem Hintergrund einer kritischen Auseinandersetzung und Abgrenzung der beiden allgemeinen und grundlegenden Deutungen, demzufolge der Totalitarismus entweder als >Religionsersatz $\prec$ zu verstehen sei oder seinen Ursprung auf den Begriff der »revolutionären Demokratie« zurückführe, dessen Glaube an die »Herrschaft >des Volkes « sowie der abstrakten Idee des volonté générale wurzelt, ${ }^{757}$ ging es Löwenthal in seinem Aufsatz um eine genaue Analyse der spezifischen Bedingungen, unter denen sich die modernen Einparteienstaaten konstituieren konnten und in deren Folge sie ihre Ideen sozusagen Wirklichkeit werden ließen. Für ihn lag der Schlüssel zum »Verständnis des Totalitarismus« darin, dass die westliche Zivilisation in der ersten Jahrhunderthälfte mit sozialen Wandlungsprozessen von einer einzigartigen Schnelligkeit konfrontiert war. Löwenthal war es darum zu tun, »das Problem« von einer anderen Seite zu beleuchten, und das bedeutete für ihn: „Statt nach dem Ursprung des totalitären Satanismus zu forschen, schlage ich vor, die Unzulänglichkeiten der freien Gesellschaftsformen in der heutigen Situation zu untersuchen. « ${ }^{758}$

Der ehemalige Anhänger der kommunistischen Bewegung wollte expressis verbis den komplexen politischen und gesellschaftlichen Entstehungsbedingungen nachgehen, die dazu führten, dass in den Jahren nach dem Ersten Weltkrieg im Kontext von »katastrophenähnlichen soziale[n] Umwälzungen« bei »Millionen von Menschen« die Vorstellung grassierte, die »Freiheit aufzugeben« und das »Heil in der Allmacht des Staates « zu suchen. Löwenthals Ansicht zufolge konnte das "geistige Desperadotum der echten totalitären Elemente« historisch nur dort wirksam werden, wo es sich mit der »materiellen Not der Massen« vereinigte. Dazu konnte es indes nur kommen, weil »die Gesellschaft« die konkreten und dringlichsten Probleme nicht lösen konnte, die »ihr die unkontrollierten Wandlungsprozesse« aufbürdeten. Das hieß mit Blick auf die »Machterringung« der totalitären Bewegungen in Russland und Deutschland:

Der Bolschewismus hätte trotz all seiner geistigen Vorgänger innerhalb der russischen Intelligenz im Jahre 1917 nicht die Macht erringen können, wenn seine Gegner willens und fähig gewesen wären, den Krieg sofort zu beenden und den Boden zu verteilen. Der Nationalsozialismus hätte trotz seiner Verwurzelung in der deutschen Ceistesgeschichte 1933 nicht gesiegt, wenn die herrschenden Parteien der Weimarer Republik damals die Keynes'sche Vollbeschäftigungspolitik verwirklicht hätten.

Und weiter schrieb er in diesem Zusammenhang:

756 Ebd., S. $3 f$.

757 Siehe im Einzelnen ebd., S. 4.

758 Ebd., S. 5 . 
Eine Analyse, die die entscheidende Bedeutung dieser fast banalen politischen, wirtschaftlichen und sozialen Probleme für den Sieg oder die Vernichtung des Totalitarismus in den Vordergrund rückt, scheint weniger tiefgründig zu sein als eine, die um den Claubensverlust des Menschen und seine damit verbundene Rebellion gegen die menschliche Seinslage kreist. ${ }^{759}$

Für Löwenthal entstanden also die totalitären Diktaturen des Sowjetkommunismus und des Nationalsozialismus auch und vor allem dadurch, dass sie angesichts des radikalen sozialen Umbruchs der jeweiligen traditionellen (Industrie-)Gesellschaften für Millionen von Menschen eine "Alternativlösung« für die spezifischen Probleme des Landes verkörperten. Aus diesem Grund erklärte sich für ihn auch die »relative Dauerhaftigkeit« des Totalitarismus, denn im Gegensatz zu den traditionellen freien Gesellschaften, die durch spontane und unzusammenhängende Änderungen gekennzeichnet waren, konnte er als eine »Maschinerie zentral geleiteter Änderungen« aufgefasst werden. »Eben hierin«, so Löwenthal mit dem Blick auf die zentralen charakteristischen Merkmale der totalitären Diktaturen des 20. Jahrhunderts,

aber liegt die Stärke des Totalitarismus als eines stabilen Regierungssystems und auch die Rechtfertigung, die er für alle seine Schrecken liefert. Er löscht Freiheit und Sicherheit des Einzelnen aus, er leugnet die Ideen der Wahrheit und Cerechtigkeit, er versucht jede Spur einer unabhängigen Entwicklung zu beseitigen, nicht um nach Art des alten Despotismus den status quo zu aufrechtzuerhalten, sondern um das Risiko eines »anarchischen « und unvorhersehbaren Wechsels zu vermeiden. Er will die Gewissheit einer »geordneten« Entwicklung nach einem vorgefaßten Plan, dem das Wertesystem der totalitären Bewegung und deren Auffassung von Zukunft und Ziel der Cesellschaft zugrunde liegt. Der Staat muß allmächtig sein, denn er ist zum Demiurgos der Gesellschaft geworden; die Partei will ihre Herrschaft dadurch verewigen, daß sie in Form einer »ständigen Revolution von oben« die Entwicklung der Cesellschaft in künstliche Bahnen zwängt; ohne den Rückhalt der diktatorischen Macht würde nämlich die entstehende Struktur sofort zusammenbrechen. ${ }^{760}$

\subsection{Der Vergleich der nationalsozialistischen und stalinistischen Konzentrationslager}

Bekanntlich war es Arendt, die in ihrem Standardwerk der Totalitarismustheorie, der 1951 erschienenen Studie The Origins of Totalitarianism, die überragende Bedeutung des Systems der Konzentrationslager für die ihrer Ansicht nach genuin neuartige Herrschaftsform hervorhob, die sie mit dem Adjektiv totalitär klassifizierte. Insbesondere mit Blick auf den Nationalsozialismus und den Sowjetkommunismus wurde das System der Konzentrationslager für die Autorin und frühe Mitarbeiterin des Monat zum Inbegriff der totalitären Herrschaftsform. Vor diesem Hintergrund konnte es im Grunde genommen auch nicht verwundern, dass gleich in der ersten Ausgabe der internationalen Zeitschrift im Oktober 1948 in zwei Beiträgen zum aktuellen Totali-

759 Ebd., S. 6.

760 Ebd., S. 7; Hervorh. des Verf. 